\title{
Hidden Hybridization and Habitat Differentiation in a Mediterranean Macrophyte, the Euryhaline Genus Ruppia
}

\author{
Lise Beirinckx $^{1 *}$, Bram Vanschoenwinkel ${ }^{2,3}$ and Ludwig Triest ${ }^{1}$ \\ ${ }^{1}$ Ecology and Biodiversity Research Group, Plant Biology and Nature Management, Vrije Universiteit Brussel (NUB), \\ Brussels, Belgium, ${ }^{2}$ Community Ecology Laboratory, Department of Biology, Vrije Universiteit Brussel (NUB), Brussels, \\ Belgium, ${ }^{3}$ Centre for Environmental Management, University of the Free State, Bloemfontein, South Africa
}

OPEN ACCESS

Edited by:

Miroslav Obornik, Institute of Parasitology (ASCR),

Czechia

Reviewed by:

Wei Wu,

Zhongkai University of Agriculture and Engineering, China Isabel Marques,

University of Lisbon, Portugal

${ }^{*}$ Correspondence: Lise Beirinckx

Lise.Beirinckx@vub.be

Specialty section:

This article was submitted to Marine and Freshwater Plants,

a section of the journal

Frontiers in Plant Science

Received: 02 December 2019

Accepted: 22 May 2020

Published: 10 July 2020

Citation:

Beirinckx L, Vanschoenwinkel B

and Triest $L$ (2020) Hidden

Hybridization and Habitat

Differentiation in a Mediterranean

Macrophyte, the Euryhaline Genus

Ruppia. Front. Plant Sci. 11:830.

doi: 10.3389/fp/s.2020.00830
In many aquatic plant taxa, classification based on morphology has always been difficult. Molecular markers revealed that the complexity in several of these aquatic taxa could be addressed to recurrent hybridization events and cryptic species diversity. The submerged macrophyte genus Ruppia is one of these aquatic genera with a complex taxonomy due to the absence of clear distinguishable traits and several hybridization events. Two species co-exist throughout Europe, $R$. maritima and $R$. spiralis (previously known as $R$. cirrhosa), but recent molecular studies also found several indications of hybridization, introgression and chloroplast capture between these species. However, the full extent and frequency of hybridization and introgression in this genus has not been studied so far, nor is it clear how these hybrid lineages can co-exist locally with their parental species. In this paper, we wanted to detect whether a single coastal wetland where both species co-exist can act as a Ruppia hybrid zone. As a case study, we chose the Camargue, a Mediterranean coastal wetland that harbors a wide diversity in aquatic habitats, especially in terms of salinity and hydro-regime. We sampled several Ruppia populations within this wetland. To identify each sample and reconstruct the local genetic structure of the two parental species and their hybrids, we used both chloroplast and nuclear microsatellite markers. Afterward, we tested whether different species had different habitat preferences. Our results confirmed that $R$. maritima and $R$. spiralis are two strongly divergent species with different reproductive ecologies and different habitat preferences. This prevents frequent hybridization and consequently we could not detect any trace of a recent hybridization event. However, we found several populations of later-generation hybrids, including a population of $R$. maritima $x$ hybrid backcrosses. The hybrid populations occupy a different habitat and are genetically distinct from their parental species, although they tend to be morphological similar to parental $R$. maritima. Although local hybridization and introgression in Ruppia is less frequent than we expected, the taxonomy of Ruppia is complicated due to ancient hybridizations and several back-crossings.

Keywords: Ruppia, hybridization, habitat differentiation, cryptic diversity, coastal wetlands, microsatellites 


\section{INTRODUCTION}

Natural hybridization is an important mechanism in plant evolution. Newly formed hybrids can have traits that allow them to colonize new niches that are not occupied by their parental species (Arnold, 1997). Different models and examples predict that hybrid lineages are more likely to persist if they can colonize new niches because this enhances reproductive isolation (Buerkle et al., 2000; Kagawa and Takimoto, 2018) and avoids competition with the parental species (Cruzan and Arnold, 1993). For instance, Helianthus species found in extreme habitats such as the desert floor or salt marshes have hybrid origins (Rieseberg et al., 2007). In willows, persistent hybrid populations can co-exist with their parental species because they occupy more extreme niches in terms of temperature, nutrients and soil pH (Gramlich et al., 2016). However, in the absence of strong reproductive isolation, hybridization can be followed by one or several backcrosses with one of the parental species. This process is called introgression and allows gene flow between different species. It can strongly disrupt classic phylogenies based on one or more genes (Baack and Rieseberg, 2007; Mallet et al., 2016). If there is no selection for these introgressed genes and hybridization is rare, the traces of hybridization in the nuclear genome decrease after several generations of back-crossings. Eventually, this can result in chloroplast capture where the chloroplast which is maternally inherited- is an introgressed organelle that has a different origin than the nuclear DNA (Rieseberg and Soltis, 1991; Tsitrone et al., 2003; Chan and Levin, 2005). As a result, introgression and chloroplast capture can be important indications for ancient hybridization beyond F1 and further generation hybrids (Masembe et al., 2006; Martin and Jiggins, 2017). These different levels of hybridization make it difficult to detect hybrids based on morphology. Besides, although several hybrid lineages are known to have an intermediate phenotype compared to the parental species or have a mosaic phenotype that combines characteristics from both parents (Burke et al., 1998; Tovar-Sánchez and Oyama, 2004; Salamone et al., 2013; Rüegg et al., 2019), this is not a general rule (Rieseberg, 1995). Many hybrids tend to resemble only one of their parental species (e.g., Rieseberg, 1995; Kaplan et al., 2009; Les et al., 2010; Takahashi et al., 2015) or hybrids can resemble other hybrids, although they have different parental species (Zou et al., 2017). Molecular markers have been essential to identify hybrid lineages and detect evidence of hybridization and introgression. However, detection of hybrids remains difficult and they can still complicate species delimitation and taxonomy (Duminil and Di Michele, 2009; Twyford and Ennos, 2012; Mallet et al., 2016).

The submerged macrophyte genus Ruppia is an example of a taxon in which hybridization, introgression and chloroplast capture have blurred taxonomy and species delimitation. The genus is distantly related to the seagrass family Posidoniaceae (Les et al., 1997) and well-known for its ability to cope with fluctuations in water-level and salinity (Verhoeven, 1979; den Hartog and Kuo, 2007). Taxonomy and identification within Ruppia have always been difficult because of the high morphological variability between populations and the absence of clear vegetative traits to distinguish different species (den Hartog and Kuo, 2007), a problem often encountered in aquatic plant taxa (Barrett et al., 1993). Throughout Europe, two Ruppia species are traditionally recognized, Ruppia maritima L. and Ruppia cirrhosa (Petagna) Grande (Reese, 1962; Verhoeven, 1979). However, recent scrutiny of the description of the lectotypification of $R$. cirrhosa concluded that this name has been used wrongly. Based on other herbarium specimens and species descriptions, Ruppia spiralis L. ex Dumortier is suggested as a more correct name, which will be used from hereon (Ito et al., 2017; den Hartog and Triest, 2020). The two species are most easily distinguished by their flower peduncle length. $R$. spiralis has long spiraling peduncles $(>5 \mathrm{~cm})$ which ensure the flowers to reach the water surface. This allows so-called epihydrophilous pollination: male pollen float over the water surface to the female flowers for fertilization. R. maritima has short peduncles $(<5 \mathrm{~cm})$ and the flowers remain submerged (Figure 1D). Their flower anatomy is expected to strongly promote self-fertilization (Verhoeven, 1979). Other diagnostic characteristics are the leaf tip shape and leaf width: $R$. maritima has small leaves (2$5 \mathrm{~mm}$ ) that end in an acute leaf tip whereas $R$. spiralis leaves are broader (4-11 $\mathrm{mm}$ ) and end obtusely (Verhoeven, 1979; Triest and Sierens, 2013; Mannino et al., 2015). However, these characteristics are more ambiguous, and identification remains difficult in the absence of flowers.

Molecular studies were performed to clarify the phylogenetic relationships within European Ruppia and to provide a barcoding tool to unambiguously identify Ruppia species. They confirmed that $R$. maritima and $R$. spiralis are two separate genetic entities that can be placed in different chloroplast haplogroups (Ito et al., 2010; Triest and Sierens, 2010), have different ITS- regions (Ito et al., 2013; Triest and Sierens, 2013) and amplify different sets of microsatellite markers (Triest et al., 2017). Combining these molecular studies with ecological data, $R$. maritima is considered as a diploid, predominantly selfing species with an annual life cycle and a high seed set (Triest and Sierens, 2015).

Tetraploid $R$. spiralis has both annual and perennial populations (Verhoeven, 1979; Gesti et al., 2005). This species can reproduce sexual through outcrossing or vegetative through underground rhizomes. The importance of either sexual or vegetative reproduction highly varies between populations. This is not only reflected in the big differences in clonality between populations but also in the large variation in number of flowers and seed production (Martínez-Garrido et al., 2016, 2017; Triest et al., 2018). Unambiguous identification has also led to the suggestion that $R$. spiralis and $R$. maritima might have different habitat preferences: $R$. spiralis is expected to prefer larger and more permanent waterbodies (Verhoeven, 1979; Triest and Sierens, 2013; Mannino et al., 2015; Martínez-Garrido et al., 2016) whereas $R$. maritima might prefers smaller and more ephemeral habitats (Verhoeven, 1979; Triest and Sierens, 2013). However, several authors also reported $R$. maritima in permanent waterbodies (Verhoeven, 1979; Mannino et al., 2015).

Furthermore, these molecular studies also found several indications of hybridization events. So far, three groups of hybrids have been detected. The first hybrid lineage has a unique haplotype, the so-called haplotype $\mathrm{E}$, that is unrelated 
to the R. maritima haplotypes, but its nuclear DNA is related to $R$. maritima. Therefore, this lineage is thought to be the result of an ancient chloroplast capture event between a currently unknown and probably extinct taxon as the maternal parent and R. maritima as pollen donor (Ito et al., 2013; Triest and Sierens, 2015; Martínez-Garrido et al., 2016). The second group of hybrids is the outcome of a $R$. spiralis $x$ haplotype group $E$ hybridization event, eventually followed by backcrossings with haplotype group E (Ito et al., 2013; Martínez-Garrido et al., 2016). Both lineages were detected in the Mediterranean, a potential hotspot for Ruppia diversification (Triest and Sierens, 2014). The third hybrid lineage was detected at the Atlantic coast in France and is characterized with a $R$. spiralis haplogroup, but the nuclear DNA seems introgressed with $R$. maritima. This lineage probably originated from a hybridization event between $R$. spiralis as the maternal parent and $R$. maritima as a pollen donor, probably followed by several back-crossings with $R$. maritima as pollen donor. The latter two lineages are both characterized by $R$. spiralis haplotypes. Although none of the encountered hybrid populations were described in detail in terms of ecology or morphology, microsatellite data suggest that they can reproduce sexually through outcrossing (Triest and Sierens, 2015; Martínez-Garrido et al., 2016).

Hybrid zones are secondary contact zones between two species (Harrison and Larson, 2016) and provide ideal study areas to investigate the frequency and consequences of hybridization events (Barton and Hewitt, 1985). In a classic hybrid zone, both parental species are found, often at the edge of their range, together with their mutual F1 hybrids. If these F1hybrids are fertile, later-generation hybrids and backcrosses to either parental species can be found as well. In the parental populations around the hybrid zone, some levels of introgression can often be detected. However, hybridization can occasionally result in new combinations of traits that allow these hybrids to outperform their parental species under particular ecological conditions. Mosaic landscapes offer a wide range of habitats and ecological niches. They can provide opportunities for hybrids to colonize their own niche outside their parent's range without long distance dispersal. The colonization of a new niche promotes (partial) reproductive isolation which can be further enhanced by positive selection on these hybrids. Even in the presence of low gene flow with their parental species, the occupation of a new ecological niche promotes the persistence of these hybrid lineages in sympatry with their parental species (Arnold, 1997; Buerkle et al., 2000). Coastal wetland areas are characterized by a wide range of different pond types with different salinities and are hence considered as a mosaic landscape. They promote regional co-existence of $R$. spiralis and $R$. maritima within the same area (Verhoeven, 1975) and are potential Ruppia hybrid zones. Due to the large variety of habitats present, wetland areas might also provide opportunities for hybrid speciation (Arnold et al., 2012). So-far, most encountered Ruppia hybrid populations were detected unintentionally in large regional studies. As a result, the presence of Ruppia hybrid zones, and the co-occurrence of hybrid lineages and their parental species is poorly documented. In addition, it is not known to what extent Ruppia hybrids may have different niches compared to the parental species.
Our main goal was to detect different Ruppia species and possible hybrids that co-occur within a coastal wetland area. We used both chloroplast and nuclear microsatellite markers to reconstruct the genetic structure and local distribution of the different lineages and detect the origins of older or more recent hybrid lineages. Secondly, we explored potential differences in habitat use between the different lineages. We chose the Camargue as a study area, a Mediterranean coastal wetland area in the south of France that represents a potential hybrid zone. This wetland area contains a large variety of aquatic habitats that are affected by seasonal variation in salinity and water level and is known to harbor both $R$. maritima and R. spiralis populations (Verhoeven, 1975; Triest and Sierens, 2014, 2015). The detection of F1 hybrids or recent introgression events would confirm that coastal wetlands could act as a Ruppia hybrid zone. The presence of hybrids of an older origin, as well as differences in habitat preference between different lineages could indicate the occurrence of hybrid speciation.

\section{MATERIALS AND METHODS}

\section{Sampling Strategy and Habitat Types}

Ruppia plants were sampled in May 2014 from twenty locations within the French regional park of the Camargue (Figure 1A). In each location, we collected thirty different ramets at $1.5 \mathrm{~m}$ intervals along a linear transect. Each location corresponded to a delineated waterbody, and hence to a potential different population. Two populations were found within the same ditch system (populations D5 and D6) but were separated by $>200 \mathrm{~m}$ of bare soil. Four populations (T2, T3, T4, and D1) were found in ponds that were too small to make a linear transect of $50 \mathrm{~m}$ hence sampling distance was reduced to $0.5 \mathrm{~m}$. In total, we collected 600 plants. Collected plant material was dried on silica gel.

During the field sampling, we already tried to give a species name to each population, based on their morphological features. We used flower peduncle length as the main discriminative characteristic: $R$. maritima has small peduncles $(<5 \mathrm{~cm})$, R. spiralis has long spiraling peduncles $(>5 \mathrm{~cm}$ ) (Figure 1D). If flowers were absent, we looked at leaf morphology. R. maritima has narrow leaves $(2-5 \mathrm{~mm})$ with an acute leaf tip, although these tips can become more obtuse-like in older leaves. $R$. spiralis has broader leaves (4-11 mm), and obtuse leaf tips (Verhoeven, 1979; Triest and Sierens, 2013). Some populations without flowers were still in an early developmental stage. In these seedlings, leaf tip was a more useful characteristic than leave width. However, in adult flowerless populations, we used a combination of leaf width and leaf tip shape for identification. We did not look at these characteristics when flowers were present. Based on the above criteria, each species could be easily addressed as either $R$. spiralis or $R$. maritima (Table $\mathbf{1}$ ).

The locations of the Ruppia populations could be categorized in three major habitat types: semi-permanent ponds, shallow temporary ponds and temporary ditches, which we, respectively, abbreviated in the population names as P, T, and D (Table 1). The semi-permanent ponds represented mainly large open 


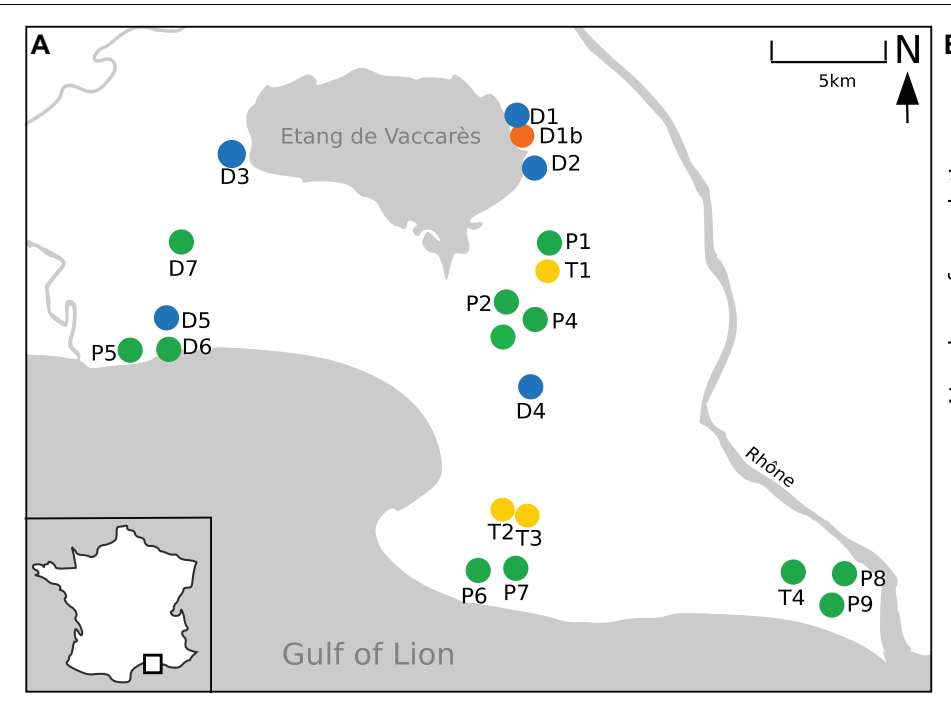

C
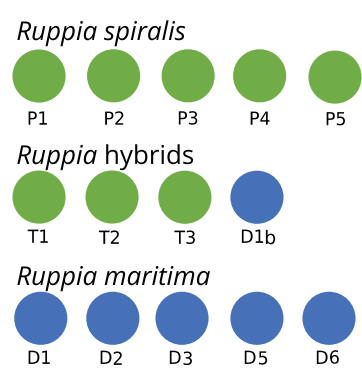

\section{Haplogroup distribution}

R. spiralis species complex haplogroups

R. maritima haplogroup

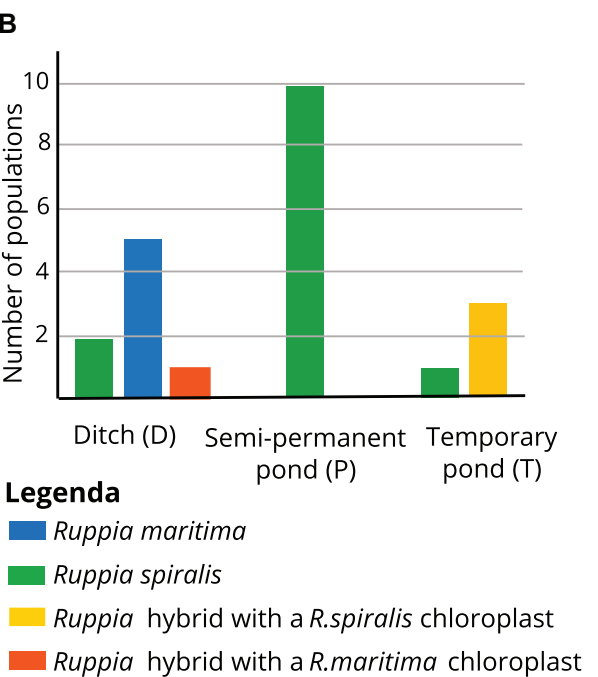

D

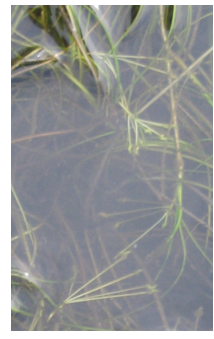

Ruppia maritima

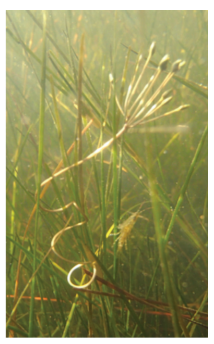

Ruppia spiralis

FIGURE 1 | Locations and pond types of the sampled Ruppia populations in the Camargue and their haplotype distribution. Panel (A) maps the locations of the sampled R. spiralis, R. maritima and hybrid populations throughout the Camargue. Three types of habitats were distinguished: ditches (indicated with a D), semi-permanent ponds (indicated with a P) and temporary ponds (indicated with a T). Panel (B) shows how many populations of each Ruppia lineage were found in each pond type. Panel (C) shows the haplogroup assignment of each population. Only one population (D1b) of a hybrid origin was characterized with a $R$. maritima chloroplast (blue), three hybrid populations had a haplotype that could be placed in the $R$. spiralis species complex group (green). This $R$. spiralis species complex comprises several haplogroups that could not be distinguished based on fragment length. A picture of $R$. maritima and $R$. spiralis can be found in panel (D): notice the long spiraling peduncle in $R$. spiralis. Hybrid population D1b can be considered as a subpopulation of pure $R$. maritima population D1: the were found as a mixed stand, within the same ditch. So far, population D1b is the first group of detected Ruppia hybrids with a R. maritima chloroplast.

waterbodies. Although pond size varies seasonally, all semipermanent ponds had a surface area of more than $100 \mathrm{~m}^{2}$ during the sampling period. Depth during sampling was highly variable, ranging between 30 and $110 \mathrm{~cm}$. Although the shallow outer margins of these ponds can dry out during summer, they only occasionally desiccate completely. Most of them are part of the large Vaccarès pond system or are abandoned salt pans. The second pond type, the temporary ponds, were shallow depressions in the dunes or salt marshes. These depressions are filled with rainwater during autumn and winter, but gradually dry during spring and summer. By the end of June, they are completely dry, leaving a cracked soil behind. This habitat type is particularly prone to yearly variation in temperature and rainfall (Verhoeven, 1975). During sampling, all temporary ponds were smaller than $100 \mathrm{~m}^{2}$, less than one meter deep and already reaching the end of their flooded season. The temporary ditches are the third pond type. They are characterized by steep sides and are clearly delineated. During sampling, water depth was more than one meter. The ditches are temporary habitats, but their hydro-regime is unpredictable because several of these ditches are regulated by sluices or used for agricultural wastewater. They have a typical linear shape but estimating the surface of these waterbodies is difficult because they are often part of a large and interconnected ditch system. Using the abovementioned criteria, all locations could be easily categorized in one of these three habitat categories.

\section{DNA Extraction and Marker Selection}

Plant DNA was extracted from dried leaf tissue using the E.Z.N.A (R) HP Plant DNA Mini Kit Protocols (Omega BioTek, Norcross, GA, United States). To genotype each specimen, we used a set of species-specific nuclear microsatellite markers that were combined in a multiplex reaction as well as a set of four chloroplast DNA markers. We used a QIAGEN multiplex PCR Plus kit to generate DNA-fragments with a PCR reaction in a thermal cycler (MJ research PTC-200 and Bio-Rad My Cycler). These fragments were run on an ABI3730XL sequencer 
TABLE 1 | List of sampled populations with the population names (Pop), number of ramets sampled in each population (Ramets), number of multilocus genotypes

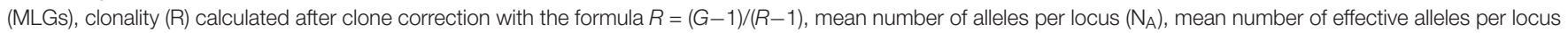

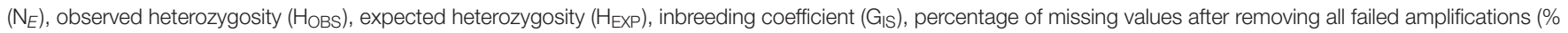
missing values), the salinity measured at the moment of sampling (salinity) and the peduncle length of a flower if flowers were present.

\begin{tabular}{|c|c|c|c|c|c|c|c|c|c|c|c|}
\hline Pop & Ramets & MLGs & $\mathbf{R}$ & $\mathbf{N}_{\mathbf{A}}$ & $\mathbf{N}_{E}$ & $\mathrm{H}_{\mathrm{OBS}}$ & $\mathbf{H}_{\mathrm{EXP}}$ & $\mathrm{G}_{\mathbf{I S}}$ & Missing values (\%) & Salinity $(\mu \mathrm{s} / \mathrm{cm})$ & Flower peduncle length \\
\hline \multicolumn{12}{|c|}{ R. spiralis } \\
\hline P1 & 29 & 29 & 1.00 & 5.23 & 2.59 & 0.61 & 0.54 & -0.08 & $11.8 \%$ & 24.4 & $>5 \mathrm{~cm}$ \\
\hline P2 & 12 & 12 & 1.00 & 4.77 & 2.37 & 0.57 & 0.59 & 0.04 & $24.4 \%$ & 39.6 & Flowers absent \\
\hline P3 & 30 & 30 & 1.00 & 6.58 & 3.13 & 0.65 & 0.65 & 0.00 & $12.6 \%$ & 35.2 & Flowers absent \\
\hline P4 & 10 & 10 & 1.00 & 2.92 & 2.11 & 0.68 & 0.52 & -0.25 & $9.3 \%$ & 31.2 & Flowers absent \\
\hline P5 & 25 & 3 & 0.08 & 2.69 & 1.90 & 0.74 & 0.41 & -0.81 & $14.6 \%$ & 25.3 & $>5 \mathrm{~cm}$ \\
\hline P6 & 28 & 28 & 1.00 & 5.46 & 2.82 & 0.64 & 0.57 & -0.09 & $21.9 \%$ & 57.4 & $>5 \mathrm{~cm}$ \\
\hline P7 & 25 & 17 & 0.67 & 6.00 & 2.95 & 0.74 & 0.59 & -0.24 & $23.4 \%$ & 56.4 & Flowers absent \\
\hline P8 & 19 & 18 & 0.94 & 5.92 & 3.42 & 0.77 & 0.65 & -0.20 & $8.6 \%$ & 12.3 & Flowers absent \\
\hline P9 & 17 & 17 & 1.00 & 6.15 & 3.00 & 0.76 & 0.63 & -0.21 & $13.9 \%$ & 14.9 & Flowers absent \\
\hline D6 & 30 & 29 & 0.97 & 5.50 & 2.87 & 0.63 & 0.55 & -0.17 & $12.7 \%$ & 63.8 & $>5 \mathrm{~cm}$ \\
\hline D7 & 29 & 28 & 0.96 & 6.75 & 3.17 & 0.64 & 0.58 & -0.07 & $14.8 \%$ & 62.1 & Flowers absent \\
\hline $\mathrm{T} 4$ & 8 & 8 & 1.00 & 4.00 & 2.60 & 0.71 & 0.58 & -0.19 & $20.1 \%$ & 69.4 & $>5 \mathrm{~cm}$ \\
\hline \multicolumn{12}{|c|}{ R. maritima } \\
\hline D1 & 16 & 2 & 0.06 & 1.10 & 1.03 & 0.00 & 0.02 & 1.00 & $3.1 \%$ & 41.4 & $<5 \mathrm{~cm}$ \\
\hline D2 & 13 & 1 & 0.00 & 1.01 & 1.00 & 0.00 & 0.00 & / & $3.1 \%$ & 39.1 & $<5 \mathrm{~cm}$ \\
\hline D3 & 25 & 2 & 0.04 & 1.10 & 1.04 & 0.00 & 0.03 & 1.00 & $3.2 \%$ & 34.3 & $<5 \mathrm{~cm}$ \\
\hline D4 & 15 & 2 & 0.07 & 1.10 & 1.05 & 0.00 & 0.03 & 1.00 & $11.3 \%$ & 52.8 & $<5 \mathrm{~cm}$ \\
\hline D5 & 21 & 1 & 0.00 & 1.00 & 1.00 & 0.00 & 0.00 & / & $2.9 \%$ & 63.8 & $<5 \mathrm{~cm}$ \\
\hline \multicolumn{12}{|c|}{ Hybrids with R. spiralis markers } \\
\hline $\mathrm{T} 1$ & 26 & 14 & 0.52 & 2.23 & 1.60 & 0.43 & -0.07 & 0.52 & $27.2 \%$ & 16 & $<5 \mathrm{~cm}$ \\
\hline T2 & 22 & 6 & 0.24 & 1.60 & 1.46 & 0.24 & -0.22 & 0.24 & $36.5 \%$ & 62.1 & $<5 \mathrm{~cm}$ \\
\hline T3 & 22 & 22 & 1.00 & 3.30 & 1.81 & 0.34 & 0.04 & 1.00 & $51.5 \%$ & 69.4 & $<5 \mathrm{~cm}$ \\
\hline D1b & 14 & 4 & 0.23 & 1.45 & 1.38 & 0.27 & 0.19 & -0.42 & $30.1 \%$ & 41.4 & $<5 \mathrm{~cm}$ \\
\hline \multicolumn{12}{|c|}{ Hybrids with R. maritima markers } \\
\hline $\mathrm{T} 1$ & 26 & 26 & 1.00 & 4.67 & 2.69 & 0.40 & 0.53 & 0.25 & $52.1 \%$ & 16 & $<5 \mathrm{~cm}$ \\
\hline $\mathrm{T} 2$ & 22 & 19 & 0.86 & 3.50 & 1.77 & 0.12 & 0.39 & 0.69 & $32.5 \%$ & 62.1 & $<5 \mathrm{~cm}$ \\
\hline T3 & 22 & 13 & 0.57 & 1.60 & 1.20 & 0.15 & 0.12 & -0.22 & $2.7 \%$ & 69.4 & $<5 \mathrm{~cm}$ \\
\hline D1b & 14 & 12 & 0.84 & 3.10 & 1.75 & 0.23 & 0.35 & 0.36 & $30,1 \%$ & 41.4 & $<5 \mathrm{~cm}$ \\
\hline
\end{tabular}

(Macrogen, Seoul, South Korea). We manually scored the results with GeneMarker V2.20 (SoftGenetics LLC ${ }^{\circledR}$ ).

Previous work on Ruppia revealed that very few microsatellites can cross-amplify in both species (Triest et al., 2017). Therefore, we genotyped each sample with a set of species-specific microsatellite markers that corresponded with their fieldidentification. Populations that we considered as R. maritima were genotyped with a set of eleven nuclear microsatellite markers that were originally developed on this species (Triest and Sierens, 2015). Assumed R. spiralis populations were genotyped with a set of fifteen microsatellites. This species-specific set comprised eleven microsatellite markers that were designed on $R$. spiralis plant material (Triest et al., 2017), as well as microsatellite marker RUMR4 that was originally designed on Chinese Ruppia sinensis plant material (Yu et al., 2009). The $R$. spiralis marker set also included three markers from the R. maritima multiplex (RMB5, RMB53, and RMB15) that are known to amplify well in several but not all $R$. spiralis populations (Triest et al., 2017). All populations had a variable number of samples with bad amplifications, which resulted in missing data. To visualize the amplification success of different markers (Figures 2A,B), both on population and individual level, we used R-package Poppr (Kamvar et al., 2014, 2015; R Development Core
Team, 2018). We removed all samples where more than $50 \%$ of the markers had a poor or failed amplification result.

Because previous studies have already shown that morphological identifications of Ruppia are not always reliable (Ito et al., 2010; Triest and Sierens, 2013; Martínez-Garrido et al., 2016), we complemented each microsatellite genotype with a cpDNA haplotype. Using the sequences of four cpDNA markers [ccmp2, ccmp3, ccmp10 (Weising and Gardner, 2002) and TrnH-psbA (Kress and Erickson, 2007)], Triest and Sierens (2014) could distinguish various haplogroups within European Ruppia populations. Haplogroup D corresponds to $R$. maritima and is only far related to the remaining haplogroups (A, B, C, and $\mathrm{E}$ ), that could be placed in a R. spiralis species complex. Although we considered amplicon length from a fragment analysis of these four cpDNA markers instead of their sequences, we should be able to distinguish at least both major species complexes (Triest and Sierens, 2014).

\section{Hybrid Detection}

Usually, hybrids are detected with several microsatellite markers that have diagnostic alleles in both parental species (Buerkle, 2005). However, good cross-amplifying markers are lacking in Ruppia (Triest et al., 2017). As a consequence, we could not 

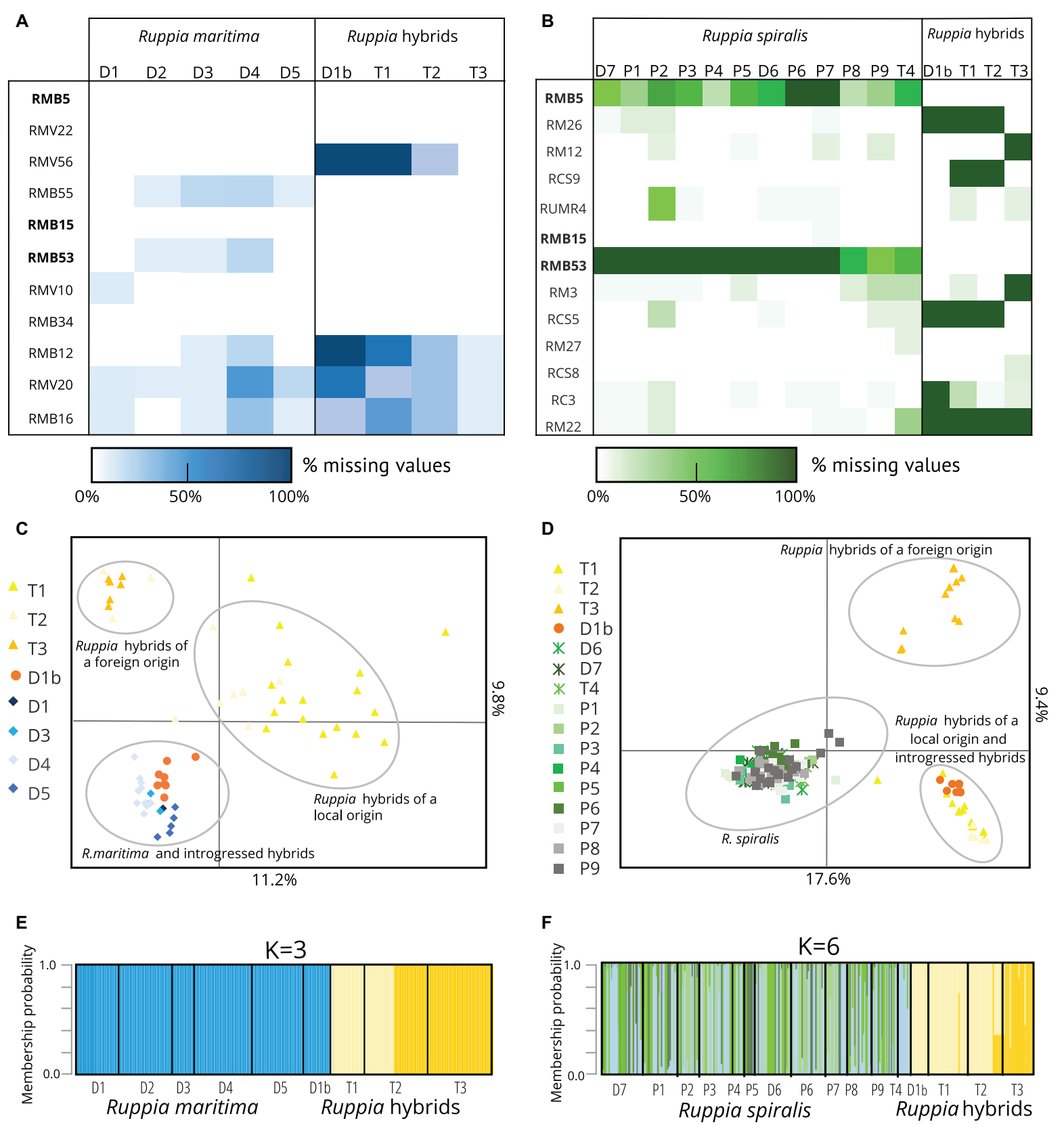

FIGURE 2 | Overview of parental Ruppia lineages and two distinct groups of hybrids detected using two sets of microsatellite markers in the Camargue area. It is important to note that parental species only amplified using markers designed for that particular species while hybrids were amplified using both primer sets. Panels (A,B) show the amplification success of different lineages with the $R$. maritima specific markers and the $R$. spiralis specific markers, respectively. The markers in bold are the three assumed cross-amplifying markers, and where used in both sets of markers. In panels (C,D), we see the clustering of different genetic lineages based on the alleles detected using both marker sets in a principal component analysis. Finally, panels (E,F) show the results of a complementary DAPC. This analysis shows the assignment of different genotyped individuals to clusters defined by the method. The principal component analysis (C,D) and the discriminant analysis of principal components $(\mathbf{E}, \mathbf{F})$ confirm the strong genetic differentiation between the hybrid populations and the pure species as well as the presence of two hybrid clusters. Based on the alleles present in the parental species, one group is expected to have a local origin, the other is presumably foreign. The eight samples of population D1b turn out to be backcrosses between the hybrids and $R$. maritima: they cannot be distinguished from pure R. maritima with the R. maritima markers, but group together with the hybrids when we used the $R$. spiralis markers.

compare these two species and their putative hybrids in the same analysis and had to search for different methods to detect hybrids. As starting point, we had the morphological species determination for each sample, the species determination based on the chloroplast markers and the nuclear genotype based on one set of species-specific markers. If we assumed that a 
population had a hybrid origin, we amplified these samples also with the other species-specific nuclear microsatellite set.

First, we examined whether the species name we assigned to a population based on the morphological identification corresponded with the cpDNA identification. If there was a mismatch, we also amplified these populations with the microsatellite set that corresponded with the cpDNA. This allowed us to detect chloroplast capture or strong introgression and corrected for inaccurate morphological identifications.

Secondly, we looked for diagnostic alleles in the markers RUMR4 and RM3, both part of the R. spiralis multiplex. These markers were previously extensively tested on $R$. spiralis and $R$. maritima samples from all over Europe, including samples from the Camargue (Triest and Sierens, 2015; Triest et al., 2017). Both RM3 and RUMR4 had good amplification results in both species and alleles differed, respectively, at least seven and ten base pairs between $R$. spiralis and $R$. maritima. However, despite their diagnostic capabilities, these markers were not included in the $R$. maritima marker set because they are monomorphic in this species (Triest et al., 2017). In cross-amplifying markers, it is always uncertain to what extent these markers are able to describe the true genetic variation in both parental species, hence markers with little variation in one parental species should be handled with care (Thielsch et al., 2012). Therefore, we preferred to include mainly markers that could detect at least some variation in the $R$. maritima multiplex, especially when we take into account how little variation was previously found in this species (Triest and Sierens, 2015). Hybrids of a recent origin are hypothesized to have both diagnostic alleles.

Thirdly, we checked the three nuclear markers that were used in both microsatellite sets (RMB5, RMB53, and RMB15). Although these markers are known to amplify in both species, the amplification success in $R$. spiralis is highly variable across populations and they have a strong overlap in alleles between the two species (Triest et al., 2017). Therefore, the amplification success of these markers in $R$. spiralis populations could rather be a signal of an introgression event instead of a shared ancestral locus. If amplification is successful in both species, the distribution of alleles could provide information about the origin of a hybrid.

To visualize the population structure and the differences in microsatellite signature between either pure species or hybrid lineages, we constructed two Principal Component Analyses (PCA). We used R-package Adegenet for this analysis (Jombart, 2008; Jombart and Ahmed, 2011; R Development Core Team, 2018). The first PCA contains all samples that are genotyped with the $R$. maritima marker set (i.e., pure $R$. maritima and hybrid populations), the second PCA comprises all samples that are visualized with the $R$. spiralis markers (i.e., pure $R$. spiralis and hybrid populations) (Figures 2C,D). To check for the hidden population structure and clustering, we complemented both PCA's with a Discriminant Analysis of Principal Components (DAPC) for each set of microsatellites (Figures 2E,F). DAPC is also implemented in the Adegenet package and uses K-means as a clustering algorithm to infer the genetic structure. It can work with polyploid data and does not require that populations are in Hardy-Weinberg equilibrium. We used the function "compoplot" to generate a graph that addresses the membership probability of each sample to the detected clusters (Jombart et al., 2010). Genetic structure of the different lineages.

Based on the previous species assignment, we considered three different datasets: a pure $R$. maritima dataset, a pure $R$. spiralis dataset and a Ruppia hybrid dataset. For population genetic analyses, we used the software Genodive, which can work with both diploid and polyploid data (Meirmans and Van Tienderen, 2004). To assign clones, GenoDive can account for scoring errors and missing values by setting up a genetic distance threshold below which similar multilocus genotypes (MLGs) are considered as identical multilocus lineages (MLLs). Setting up the threshold, we considered a stepwise mutation model. For $R$. maritima and $R$. spiralis, we chose to ignore the missing values; in the hybrid populations, we considered them as one mutation step. GenoDive can also calculate the probability that the observed clonal structure is the result of clonal growth rather than sexual reproduction (Gómez and Carvalho, 2000). If the calculated $p$-value was smaller than 0.05 , we decided that the observed genetic structure was rather the result of sexual reproduction and all samples were kept in the population. If identical MLGs were the result of clonal growth, we kept only one representative sample in the population. After this clone-correction, we calculated the genotypic richness via $R=(G-1) /(N-1)$ in which $\mathrm{G}$ is the number of different genets and $\mathrm{N}$ the total number of individuals (Arnaud-haond et al., 2007; Table 1).

To estimate the ploidy of a population, we counted the number of different alleles for each marker. If we detected three or four alleles for at least one locus in a sample, we considered that sample as tetraploid. Because triploids are mostly sterile, we don't consider the possibility of a triploids in an outcrossing population. Besides, triploids were only rarely detected in Ruppia and never encountered in European Ruppia (Ito et al., 2010). Furthermore, if several samples in a population have three or four alleles for a single locus, we assume that the entire population is tetraploid.

Because most population statistics are developed for diploid populations, there are several restrictions for polyploids and comparisons among different ploidy levels. Above all, there is the problem of calculating observed heterozygosity: diploids have only one state of heterozygosity (e.g., AB) whereas tetraploids have partial and full heterozygotes (e.g., respectively, AABB and $\mathrm{ABCD}$ ). Secondly, there is the problem of unknown allelic dosages in heterozygotes: if a sample has two different alleles for a single locus, e.g., $A$ and $B$, it is difficult to deduct whether the true genotype is either $A A A B, A A B B$ or ABBB. This uncertainty strongly affects all allele-frequency based calculations (Dufresne et al., 2014). The software GenoDive (Meirmans and Van Tienderen, 2004) circumvents these two problems because it uses the principle of gametic heterozygosity to calculate the observed heterozygosity, which looks at the heterozygosity of the possible diploid gametes that can be drawn from a certain population (Moody et al., 1993; Meirmans et al., 2018). To counteract the problem of the unknown allelic dosages, GenoDive fills in the unknown alleles based on the observed allele frequencies in a population, following a maximum likelihood approach (De Silva et al., 
2005). These corrections allow for a more correct estimation of the allele frequencies (Supplementary Material S1) and the frequency-based parameters, such as the inbreeding coefficient $\mathrm{G}_{\mathrm{IS}}$ and fixation coefficient $\mathrm{G}_{\mathrm{ST}}$ (Nei, 1973). However, the comparison of individuals and populations with different ploidy levels remains difficult because their allele frequencies respond differently to processes such as migration or drift. Ronfort et al. (1998) developed $\rho$, a statistic that measures population differentiation, but is independent of ploidy-level, rate of self-fertilization and typical polyploid problems such as rate of double reduction or polysomic inheritance (Meirmans and Van Tienderen, 2013). Parameter $\rho$ can be calculated with GenoDive, using an AMOVA approach (Meirmans and Liu, 2018). Nevertheless, $\rho$ is still based on observed and expected heterozygosity, which remain tricky concepts in polyploids. $\mathrm{D}_{\text {est }}$ (Jost, 2008) is another statistic to measure population differentiation that is unaffected by ploidy but is calculated based on the effective number of alleles. It is also independent of population size, but is highly affected by migration and mutation rates, and hence not well suited to describe population demographics (Ryman and Leimar, 2009; Meirmans and Hedrick, 2011). Parameters $\rho$ and $D_{\text {est }}$ were both calculated for each locus, and for population pairwise distances (Table 2).

\section{Differences in Habitat Use?}

Finally, we tested for an association between genetic lineage and habitat type with a two-sided Fisher exact test in $\mathrm{R}(\mathrm{R}$ Development Core Team, 2018). We considered the three genetic entities, $R$. spiralis, $R$. maritima and the hybrids, separately and constructed a $3 \times 2$ contingency table for each showing the number of presences and absences in each of the habitat types. Pond type was considered as a three-leveled categorical variable (semi-permanent pond, temporary pond and ditch) and presence or absence of the genetic entity as a categorical variable with two levels. We counted the number of populations for each pond type where this group was, respectively, present or absent (Figure 1C).

TABLE 2 | Parameters measured for each locus

\begin{tabular}{|c|c|c|c|c|c|c|c|c|c|c|c|c|c|c|c|c|c|c|}
\hline & \multicolumn{9}{|c|}{ Ruppia spiralis } & \multicolumn{9}{|c|}{ Ruppia hybrids } \\
\hline & $\mathbf{N}_{\mathbf{A}}$ & $\mathbf{N}_{E}$ & $\%$ miss & $\mathrm{H}_{\mathrm{OBS}}$ & $H_{\text {EXP }}$ & $G_{I S}$ & $\mathrm{G}_{\mathrm{ST}}$ & $\rho$ & $D_{\text {EST }}$ & $\mathbf{N}_{\mathbf{A}}$ & $\mathbf{N}_{E}$ & $\%$ miss & $\mathrm{H}_{\mathrm{OBS}}$ & $\mathrm{H}_{\mathrm{EXP}}$ & $G_{I S}$ & $\mathrm{G}_{\mathrm{ST}}$ & $\rho$ & $\mathrm{D}_{\mathrm{EST}}$ \\
\hline RM26 & 14 & 4.3 & $3.0 \%$ & 0.70 & 0.80 & 0.14 & 0.10 & 0.06 & 0.43 & 6 & 1.5 & $80.8 \%$ & 0.50 & 0.80 & 0.01 & 0.34 & 0.35 & 1.00 \\
\hline RM12 & 9 & 2.7 & $3.3 \%$ & 0.89 & 0.78 & -0.30 & 0.02 & 0.08 & 0.05 & 3 & 2.0 & $33.7 \%$ & 1.00 & 0.51 & -0.98 & -0.01 & 0.83 & -0.02 \\
\hline RCS9 & 8 & 2.5 & $0.7 \%$ & 0.75 & 0.61 & -0.19 & 0.10 & 0.04 & 0.21 & 3 & 1.5 & $67.3 \%$ & 1.00 & 0.69 & -1.0 & 0.41 & 0.88 & 0.72 \\
\hline $\mathrm{RMB}^{\circ} 3^{\circ}$ & 3 & 1.3 & $93.7 \%$ & 0.35 & 0.23 & -0.54 & / & / & / & 2 & 1.0 & $1.9 \%$ & 0.00 & 0.04 & 1.00 & 0.04 & 0.25 & 0.01 \\
\hline $\mathrm{RM} 3$ & 9 & 1.7 & $7.0 \%$ & 0.55 & 0.52 & -0.34 & 0.115 & 0.20 & 0.13 & 3 & 1.0 & $36.5 \%$ & 0.00 & 0.46 & 1.00 & 0.95 & 0.78 & 0.01 \\
\hline RCS5 & 8 & 2.6 & $4.1 \%$ & 0.70 & 0.72 & -0.10 & 0.11 & 0.11 & 0.26 & 12 & 1.5 & $76.0 \%$ & 1.00 & 0.87 & -0.10 & 0.41 & 0.32 & 0.98 \\
\hline RM27 & 7 & 2.0 & $0.7 \%$ & 0.99 & 0.52 & -0.90 & -0.02 & 0.01 & -0.04 & 7 & 1.7 & $14.4 \%$ & 0.74 & 0.67 & -0.70 & 0.36 & 0.77 & 0.56 \\
\hline RCS8 & 8 & 1.9 & $1.5 \%$ & 0.62 & 0.50 & -0.22 & 0.13 & 0.09 & 0.16 & 6 & 1.3 & $22.1 \%$ & 0.04 & 0.61 & 0.72 & 0.67 & 0.67 & 0.81 \\
\hline Total & \multicolumn{9}{|c|}{ Ruppia maritima } & \multicolumn{9}{|c|}{ Ruppia hybrids } \\
\hline RMV22 & 2 & 1.1 & $3.4 \%$ & 0.00 & 0.50 & 1.00 & 0.71 & 0.79 & 0.50 & 4 & 1.6 & $1.3 \%$ & 0.29 & 0.46 & 0.19 & 0.63 & 0.61 & 0.43 \\
\hline RMV56 & 1 & 1.0 & $0.0 \%$ & 0.00 & 0.00 & / & / & / & / & 4 & 1.2 & $41.0 \%$ & 0.17 & 0.60 & 0.33 & 0.69 & 0.52 & 0.71 \\
\hline $\mathrm{RMB}^{\circ}$ & 2 & 1.1 & $1.1 \%$ & 0.00 & 0.18 & 1.00 & 0.48 & 0.45 & 0.11 & 3 & 1.1 & $1.3 \%$ & 0.00 & 0.55 & 1.00 & 0.80 & 0.45 & 0.64 \\
\hline $\mathrm{RMB}^{2} 3^{\circ}$ & 1 & 1.0 & $0.0 \%$ & 0.00 & 0.00 & / & / & / & / & 2 & 1.0 & $0.0 \%$ & 0.00 & 0.04 & 1.00 & 0.03 & 0.25 & 0.01 \\
\hline RMB55 & 1 & 1.0 & $9.1 \%$ & 0.00 & 0.00 & I & I & I & I & 13 & 1.6 & $0.0 \%$ & 0.37 & 0.71 & 0.15 & 0.59 & 0.72 & 0.62 \\
\hline $\mathrm{RMB}^{\circ} 5^{\circ}$ & 1 & 1.0 & $0.0 \%$ & 0.00 & 0.00 & I & I & I & I & 6 & 1.2 & $0.0 \%$ & 0.11 & 0.44 & 0.77 & 0.59 & 0.64 & 0.63 \\
\hline RMV10 & 1 & 1.0 & $0.0 \%$ & 0.00 & 0.00 & I & / & 1 & / & 7 & 1.9 & $0.0 \%$ & 0.32 & 0.60 & 0.41 & 0.23 & 0.42 & 0.20 \\
\hline RMB34 & 2 & 1.0 & $2.3 \%$ & 0.00 & 0.00 & 1.00 & 1.00 & 0.97 & 0.60 & 5 & 1.8 & $26.9 \%$ & 0.41 & 0.65 & 0.13 & 0.20 & 0.15 & 0.43 \\
\hline RMB12 & 1 & 1.0 & $3.4 \%$ & 0.00 & 0.48 & / & I & / & / & 7 & 1.7 & $37.2 \%$ & 0.06 & 0.80 & 0.87 & 0.53 & 0.34 & 0.86 \\
\hline
\end{tabular}

Loci that are present in both sets of markers are indicated with ${ }^{\circ} N_{A}$, number of alleles; $N_{E}$, number of effective alleles; \% miss, percentage of failed amplifications; $H_{O B S}$,

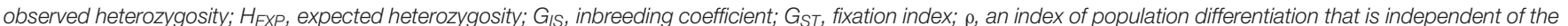

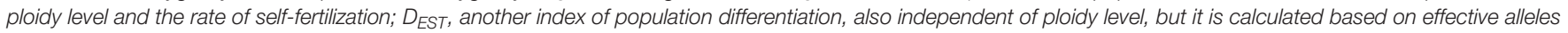
instead of observed and expected heterozygosity. 


\section{RESULTS}

\section{Detection of the Hybrids}

Based on the morphological identifications, we considered eight populations as $R$. maritima and twelve as $R$. spiralis. Each assumed $R$. maritima population had many flowering ramets with short peduncles. Out of the twelve assumed $R$. spiralis populations, five had several flowers with long spiraling peduncles, seven populations were identified as $R$. spiralis based on leaf morphology (Table 1). When these results were compared with the chloroplast haplotypes, we found that three assumed $R$. maritima populations (T1, T2, and T3) had a chloroplast that could be placed in a $R$. spiralis species complex haplogroup. Using amplicon length of the chloroplast markers, we could clearly distinguish both species complexes, however this approach did not visualize all minor variants with certainty such as obtained from sequences.

The three populations with a mismatch between the morphological identification and the cpDNA haplogroup (T1, T2, and T3) were amplified with both sets of microsatellite markers. However, the $R$. maritima specific microsatellite markers had acceptable amplification success in these three populations, the observed amplification patterns strongly differ from pure $R$. maritima. While pure $R$. maritima had a very low genetic diversity $\left(N_{\mathrm{A}}=1.3\right)$ and no heterozygotes $\left(N_{\mathrm{A}}=1.3\right.$; $H_{\mathrm{OBS}}=0.00$; see Table 1 and section "Population Genetic Structure of $R$. maritima and $R$. spiralis"), populations T1, T2, and T3 had a much higher allelic diversity $\left(N_{\mathrm{A}}=5.8\right)$ and at least some levels of observed heterozygosity $\left(H_{\mathrm{OBS}}=0.22\right)$. Besides, markers that had overall lower amplification success in the pure R. maritima populations (markers RMB12, RMV20, and RMB16), had even poorer amplification success in these three populations (Figure 2B). Marker RMV56 completely failed to amplify in population T1. These deviating patterns are also reflected in the PCA and DAPC based on the R. maritima microsatellite results (Figures 2D,F): populations T1, T2, and T3 are clearly separated from the pure $R$. maritima populations. This supports the presumption of a potential hybrid origin for populations $\mathrm{T} 1, \mathrm{~T} 2$, and $\mathrm{T} 3$.

A comparable amplification pattern is found in fourteen samples of population D1. This population is identified as $R$. maritima and all samples have a $R$. maritima chloroplast. However, these fourteen samples completely failed to amplify two microsatellite markers (RMV56 and RMB12), had several unique alleles for the remaining seven markers $\left(N_{\mathrm{A}}=3.1\right)$ and were the only $R$. maritima samples with some levels of observed heterozygosity (Table 1). All unique alleles discovered in these fourteen samples were re-encountered in assumed hybrid populations T1, T2, and T3. Therefore, we placed these samples in a subpopulation D1b and considered a potential hybrid origin for this subpopulation. Subsequently, we amplified them with the $R$. spiralis microsatellite markers.

To detect hybrids with the $R$. spiralis marker set, we first searched for diagnostic alleles with markers RUMR4 and RM3. All populations that were originally identified as $R$. spiralis had only R. spiralis diagnostic alleles (RUMR4: 124 and 126 bp; RM3: 231 and $233 \mathrm{bp}$ ). The assumed hybrid populations T1 and T2 were characterized exclusively by $R$. maritima diagnostic alleles (RUMR4: 136 bp; RM3:221 bp). Within population T3, marker RM3 did not amplify and marker RUMR4 was characterized by a unique allele of $131 \mathrm{bp}$ which was not observed before in any other Ruppia population (Triest et al., 2017). In population D1b, marker RUMR4 was always heterozygous, with both $R$. spiralis and $R$. maritima alleles in each sample. Marker RM3 only detected R. maritima alleles in population D1b. For completeness, we must add that three $R$. spiralis samples were characterized with a new RUMR4 allele (128 bp; two samples in population $\mathrm{P} 1$, one sample in population D6). Marker RM3 also detected four new alleles R. spiralis (123, 124,127 , and $129 \mathrm{bp}$ ) but none of them was encountered in $\mathrm{T} 1, \mathrm{~T} 2$, and $\mathrm{T} 3$.

Next, we considered the three cross-amplifying markers that were included in both marker sets. Markers RMB5 and RMB53 had very bad amplifications in populations with a $R$. spiralis chloroplast, except for populations T1, T2, and T3 (Figure 1B). Furthermore, they had high amplification success in all populations with a $R$. maritima chloroplast, including population D1b (Figure 1A). Marker RMB15 amplified well in all populations, but we observed differences in the number of alleles between the different Ruppia lineages. $R$. spiralis contained eleven different alleles, ranging from $161 \mathrm{bp}$ until $181 \mathrm{bp}$. In R. maritima, this marker detected only one allele (167 bp). In population D1b, 167 bp was also the most dominant allele (allele frequency $=70.0 \%$ ) out of four detected alleles (alleles 165, 169, and $175 \mathrm{bp}$ ). The assumed hybrid populations T1, T2, and T3 (R. spiralis chloroplast) are almost completely monomorphic for allele 173 (97\%) and entirely homozygous for this marker.

Finally, microsatellite amplification success was highly variable between different markers and different populations of assumed hybrids, especially in the $R$. spiralis microsatellites. Within the $R$. spiralis specific set of markers, a group of four microsatellite markers (RM26, RCS9, RCS5, and RM22) did not amplify in populations T1 and T2, another set of three markers (RM3, RM12, and - again-RM22) failed to amplify in population T3 (Figure 2B). Furthermore, the observed heterozygosity of most markers in populations T1, T2, and T3 is either (very close to) one or (approaching) zero. This indicates the presence of null alleles.

The PCA based on the $R$. spiralis markers (Figure 2D) strongly separates populations $\mathrm{T} 1, \mathrm{~T} 2, \mathrm{~T} 3$ and $\mathrm{D} 1 \mathrm{~b}$ from pure R. spiralis along the first axis, which explained $17.6 \%$ of the variation. The hybrids can also be placed in two separate groups, following the second axis (explaining 9.4\%). The first hybrid cluster contains populations T1, T2, and D1b, the second only population T3. This clustering pattern was confirmed with the DAPC (Figure 2F). We used $K=6$, based on the lowest BIC, but changing the number of clusters did not alter the pattern of two distinct hybrid clusters. This hybrid clustering pattern corresponds with the previous results where markers were shown to behave differently between populations T1-T2 and population T3. Although the amplification failure pattern (Figure 2A) is partly responsible for this structure, a closer look on the allele frequencies (Supplementary Material S1) reveals that there is very little overlap in alleles between both hybrid clusters for the 
R. spiralis marker set. Population T3 has also very few alleles in common with pure $R$. spiralis.

A similar clustering pattern could be seen in the PCA based on the R. maritima markers, although the pattern is less clear (Figure 2C). The pure $R$. maritima samples and the T3 hybrid cluster are separated from each other along the second axis (explains $9.8 \%$ of the variation). The T1-T2 hybrid cluster is spread over a larger area, comprising more variation. However, some samples of population T2 can be found in the T3-cluster. This is confirmed in the DAPC based on the R. maritima samples (Figure 2D) where some T2-samples are assigned to the T3 cluster. The $R$. spiralis DAPC already showed that these T2 samples might have a mixed origin of both clusters (Figure 2E). This suggests that gene flow between the two hybrid clusters is possible.

Finally, in the analyses based on the R. maritima markers, population $\mathrm{D} 1 \mathrm{~b}$ is grouped together with pure $R$. maritima both in the PCA (Figure 2C) and DAPC (Figure 2E). Increasing $\mathrm{K}$ in this DAPC did not set population D1b apart, nor did it increase the number of hybrid clusters. Taking into account that the $R$. spiralis marker-based analyses grouped population D1b in the T1-T2 cluster, we consider this subpopulation as a group of backcrosses between hybrids and $R$. maritima, with the hybrids as pollen donors.

Microsatellites were also used to detect ploidy levels of these hybrid populations. We found three or four alleles for at least one locus in $40 \%$ of the hybrids with a $R$. spiralis chloroplast. Therefore, we consider them as tetraploid. However, we never found more than two alleles in population D1b the hybrids with a $R$. maritima chloroplast. This indicates that this lineage might be diploid, but polyploidy might be missed due to the small sample size.

\section{Population Genetic Structure of $R$. maritima and $R$. spiralis}

The five pure $R$. maritima populations were considered as diploid, based on the current allele counts and previous studies. They had limited allelic variation with 1.7 alleles per locus on average (Table 1), low gene diversity $\left(H_{\mathrm{EXP}}=0.04\right)$ and no observed heterozygosity $\left(H_{\mathrm{OBS}}=0.00\right)$. This results in a low clonal diversity $(R=0.04)$, with only six different MLGs for all pure $R$. maritima samples (Table 3). Testing for clonal structure with GenoDive could not confirm that the observed clonal structure is truly the result of clonal growth $(p>0.05)$ and all samples were kept in the dataset for further analyses. Based on other parameters, these MLGs are rather the result of strongly inbred lineages: seven loci were monomorphic (RMV56, RMB55, RMB15, RMB53, RMV10, RMB12, and RMB16) and hence removed for further species-specific analyses (Table 2). A complete absence of heterozygosity maximized the inbreeding coefficient $\left(G_{I S}=1\right)$. As shown in Table 2, population differentiation parameters $\mathrm{G}_{\mathrm{ST}}$ and $\rho$ were very high (respectively, 0.80 and 0.82). These parameters are based both on observed and expected heterozygosity, hence the absence of observed heterozygosity in all samples will give a distorted image. Allelic differentiation
$\left(D_{\mathrm{EST}}=0.41\right)$, based on the number of effective alleles, was less biased than $G_{S T}$ and $\rho$ but is affected by the low number of polymorphic loci. The PCA and DAPC based on the $R$. maritima marker set confirmed that there is no strong population structure in this pure $R$. maritima dataset (Figure 2C).

The twelve pure $R$. spiralis were considered as tetraploids because we found three or four alleles in $60 \%$ of these samples. The populations had an overall high clonal richness (Table 1). Only two populations showed substantial clonal growth (P5 with $R=0.08$ and $\mathrm{P} 7$ with $R=0.67$ ). Testing for clonal structure revealed that these MLGs are truly the result of clonal growth $(p<0.05)$ and hence only one sample of each MLG is kept. Three populations had one or two MLGs that occurred twice (D6 with $R=0.97$, D7 with $R=0.96$ and P8 with $R=0.94$ ). We could not confirm that these MLGs were true clones $(p>0.05)$ and all samples are kept. The $R$. spiralis populations had 11.8 alleles per locus on average, but the mean number of effective alleles is 2.5, thereby indicating low evenness (Table 2). The overall heterozygosity $\left(H_{\mathrm{OBS}}=0.66\right.$ and $\left.H_{\mathrm{EXP}}=0.59\right)$ was comparable but there were large differences among loci, possibly partly as a result of tetraploidy. Overall $\mathrm{G}_{\mathrm{IS}}$ for $R$. spiralis was negative $(-0.18)$. We found little population differentiation $\left(G_{\mathrm{ST}}=0.11, \rho=0.08\right.$, and $\left.D_{\mathrm{EST}}=0.21\right)$, which is concordant with the observed pattern in both the PCA and DAPC (Figure 2). Within the DAPC, the pure $R$. spiralis samples have a scattered distribution over the four remaining clusters ( $K=6$ but two clusters belong to the hybrids), without a clear population structure. Changing the value of $K$ did not affect the pattern of hybrid clustering.

\section{Population Structure of the Ruppia Hybrids}

The three inferred hybrid populations had a genetic diversity that was intermediate to their parental species (mean number of alleles per locus $=5.0$, Table 2 ). The $R$. spiralis multiplex detected 40 alleles in the hybrid samples, of which ten were unique for the hybrids. Six of them were found exclusively in T3, sometimes strongly differing in allele lengths from the pure $R$. spiralis populations. Besides, there was also little overlap in alleles between the T1-T2 cluster and the T3 cluster. The $R$. maritima multiplex detected 64 different alleles in these hybrid samples, whereas only 17 alleles were found in pure $R$. maritima. Except for one unique allele, all $R$. maritima alleles were reencountered in the hybrid populations. Contrary to the R. spiralis marker set, population T3 has the lowest number of alleles per locus of these hybrid populations and only five unique alleles. Population $\mathrm{T} 1$ has the largest number of $R$. maritima alleles (mean allele per locus $=5.7$, Table 1 ).

We also observed strong differences between the two sets of markers in terms of clonality (Table 1 ). The $R$. maritima marker set found low clonality in T2 $(R=0.87)$ and T3 $(R=0.5)$ but clonal structure could not be confirmed for T3 $(p>0.05)$, probably due to the low number of alleles. Adding the $R$. spiralis markers, no clones could be detected anymore in T2. Overall, clonal richness was estimated at 0.89 
TABLE 3 | Distribution of the genotypes of pure R. maritima among the five pure R. maritima populations.

\begin{tabular}{|c|c|c|c|c|c|c|}
\hline & Genotype 1 & Genotype 2 & Genotype 3 & Genotype 4 & Genotype 5 & Genotype 6 \\
\hline D1 & $0 \%$ & $88 \%$ & $12 \%$ & $0 \%$ & $0 \%$ & $0 \%$ \\
\hline D2 & $0 \%$ & $0 \%$ & $0 \%$ & $0 \%$ & $100 \%$ & $0 \%$ \\
\hline D3 & $12 \%$ & $0 \%$ & $0 \%$ & $0 \%$ & $88 \%$ & $0 \%$ \\
\hline D4 & $0 \%$ & $0 \%$ & $0 \%$ & $13 \%$ & $67 \%$ & $20 \%$ \\
\hline D5 & $0 \%$ & $100 \%$ & $0 \%$ & $0 \%$ & $0 \%$ & $0 \%$ \\
\hline Total & $3 \%$ & $41 \%$ & $2 \%$ & $2 \%$ & $49 \%$ & $3 \%$ \\
\hline
\end{tabular}

with both sets of microsatellites. Considering gene diversity, we found especially large differences among the $R$. spiralis markers: three loci (RM12, RCS9, and RM27) were fixed heterozygotes for one or more hybrid populations, other loci were completely monomorphic (RM3, RM2, and RMB53) (Table 2). The observed and expected heterozygosity was more balanced for loci of the R. maritima multiplex. Overall, we found higher population differentiation among the hybrid lineages compared to the pure species.

\section{Associations Between Habitat and Genetic Lineages}

Ruppia maritima was found exclusively in temporary ditches, the hybrids exclusively in the shallow temporary ponds and $R$. spiralis was most often encountered in large semi-permanent ponds (Figure 1C). The Fisher test confirmed that these associations between each lineage and habitat type exist $(p<0.05$ for each contingency table).

\section{DISCUSSION}

In this paper, we used genetic tools to identify different lineages of the genus Ruppia that co-occur within a single Mediterranean wetland. We particularly focused on the presence of hybrid lineages. In addition, we combined both genetic and ecological data to detect differences in ecology and habitat use between these different Ruppia lineages. Our results show that both $R$. spiralis and $R$. maritima can co-occur within the same wetland area but have different reproductive ecologies and habitat preferences. We also detected several populations of later-generation hybrids. These hybrid populations occupied a distinct habitat, different from the habitat of the parental species. We could not detect any signs of recent hybridization events (F1 hybrids) or frequent introgression between $R$. spiralis and $R$. maritima, although we detected one recently backcrossed lineage, presumably between a local hybrid population and R. maritima.

\section{Different Ruppia Lineages Have Different Habitat Preferences}

We found strong differences in reproductive strategy and habitat preference between $R$. spiralis, $R$. maritima and the hybrids. $R$. spiralis was mainly found in large semi-permanent ponds but also occasionally detected in the two temporary habitat types. Previous molecular and detailed ecological studies already revealed that $R$. spiralis has a strong preference for more permanent waterbodies, including some marine environments (Verhoeven, 1979; Mannino and Graziano, 2014; Triest and Sierens, 2014; Martínez-Garrido et al., 2017; Triest et al., 2018). However, several of the R. spiralis ponds detected in this study dry out regularly during late summer. This indicates that $R$. spiralis can occupy a large range of habitats in terms of hydroperiod. Nevertheless, we consider these semi-temporary ponds as the edge of their habitat range because droughts too early in summer will prevent $R$. spiralis to complete its life cycle and produce seeds. Besides, occasional summer droughts also prevent the establishment of long-living perennial $R$. spiralis populations as were previously described in more permanent waterbodies (Gesti et al., 2005; Mannino et al., 2015). Previously, a link between clonal growth and habitat stability was suggested (Martínez-Garrido et al., 2017) but our results could not support this hypothesis. Almost all populations showed high levels of outcrossing and low levels of clonality, even the adult populations without flowers, possibly because none of the included ponds provides sufficient stability. The only highly clonal population, population $\mathrm{P} 5$, was found in an abandoned salt pan that can exhibit strong fluctuations in water level and is hence not an ecologically stable environment.

Both $R$. maritima and the hybrid populations had a strong preference for temporary waterbodies that dry out during late spring. Several authors already mentioned the preference of European $R$. maritima for more temporary habitat types (Verhoeven, 1979; Triest and Sierens, 2015) which is in accordance with their ecology: a short life cycle combined with high seed set are well-known adaptations of aquatic plants to temporary environments (Brock and Lane, 1983). But despite this known preference for temporary waterbodies, we were surprised to detect $R$. maritima only in a single very specific type of temporary waterbodies: man-made ditches with steep walls. These ditches are regulated by sluices and can undergo sudden and unexpected changes in salinity and water-level, which could impose severe stress on plants (Howard and Mendelssohn, 1999). The shallow temporary ponds, often found in small depressions in the dunes or marshes, dry out more gradually and are hence considered as a less stressful environment. However, these ponds were inhabited by Ruppia hybrid populations and a single $R$. spiralis population. This very narrow habitat range of $R$. maritima could possibly be explained by its dominantly selfing reproductive strategy. In selfing species, niche breadth is known to decrease rapidly over time, and selfing species occupy a smaller and more marginal niche compared to their 
outcrossing relatives (Totté et al., 2015; Park et al., 2018), which is consistent with the narrow habitat range observed in this study. Based on $R$. maritima flower morphology, Verhoeven (1979) already suggested that $R$. maritima is a dominantly selfing species, and this was confirmed with microsatellites by Triest and Sierens (2015). However, these authors found at least some levels of heterozygosity in most European $R$. maritima populations, whereas our populations were completely homozygous with very low levels of genetic diversity. Possibly, low levels of outcrossing are masked by this low genetic diversity and due to the low level of genetic variation, we cannot distinguish between sexual and asexual reproduction, but overall, we can conclude that the $R$. maritima populations in this study are highly selfing.

Established hybrid lineages are often found in different habitats than their parental species (Brochmann et al., 2004; Soltis et al., 2004; Abbott et al., 2013). Hybridization leads to new phenotypes and some newly formed hybrids can survive in habitats that were unfavorable to their parents. The presence of a large variety of niches close to the parental contact zone increases the chances that a new phenotype can colonize a suitable niche (Arnold, 1997). However, most established hybrid lineages are often found in environments that are more extreme in terms of environmental stress or requirements, compared to their parental niches (Burke and Arnold, 2001; Rieseberg et al., 2007; Gramlich et al., 2016). Within our study area, the Ruppia hybrids are found in the shallow temporary ponds which is a more intermediate habitat in terms of environmental stress compared to their parental habitats. It is possible that these temporary ponds were an empty gap in the Ruppia niche range. The newly formed Ruppia hybrids may have been able to colonize these shallow temporary ponds because of the absence of competitors, followed by local adaptation in the following generations (Burke and Arnold, 2001). However, hybridization can also be a mechanism to get rid of possible deleterious genetic "load," especially in genetically impoverished populations (Ellstrand and Schierenbeck, 2000). Consequently, hybrids can be more fit than their genetically poor progenitor species in their native range (Barton, 2001; Burke and Arnold, 2001). It could be hypothesized that strongly homozygous and genetically poor $R$. maritima was originally found in these shallow temporary ponds as well but had a lower fitness compared to the newly formed hybrids that invaded these habitats. Therefore, the hybrids that colonized these temporary ponds were able to locally outcompete $R$. maritima. Strong selection and local adaptation could not only decrease the niche breadth of a selfing species but also cause a niche shift (Levin, 2010), two mechanisms that might have banned $R$. maritima to the temporary ditches. Although hybrids are generally thought to be less fit than their parental species, especially in their parent's niche, several examples contradict this (Arnold et al., 2012). For instance, F1 hybrids in North American cattail were found to dominate their parents' habitats (Olson et al., 2009; Zapfe and Freeland, 2015) and later-generation hybrids between two wild species of the genus Vigna are found to be more vigorous in one parent's native habitat (Takahashi et al., 2015). However, comparisons with other Ruppia hybrid zones are necessary to validate this hypothesis, as well as more detailed descriptions of $R$. spiralis and R. maritima niches. In the long run, the increased genetic diversity in Ruppia hybrids can lead to an increased evolutionary potential which may give these hybrids a competitive advantage compared to the strongly homozygous parental R. maritima.

\section{Origin of the Hybrid Populations}

The three hybrid populations can be divided into two different genetic clusters. The first hybrid cluster comprises populations T1 and T2, the second population T3. Each cluster is characterized by a specific group of non-amplifying loci and a set of unique alleles. However, this does not mean that each cluster only groups the interbreeding offspring of a single hybridization event. If a hybrid lineage has a single origin, all hybrid alleles that were not present in the parental individuals would be the result of mutations (Soltis and Soltis, 1993). The genetic diversity in both hybrid clusters probably results from several hybridization events and backcrossing events with mutually outcrossing offspring, supplemented with new alleles due to mutations. Consequently, we assume that both clusters had multiple origins (Meimberg et al., 2009).

Comparing alleles between hybrids and parental species can reveal information about the origin of these hybrids. The $R$. spiralis markers suggested that both hybrid clusters had very little overlap in alleles. The alleles in the T1-T2 cluster largely correspond to those in the local R. spiralis populations. However, the T3 cluster had many unique alleles that strongly differ from the current local R. spiralis populations. As a result, we assume a local origin for the T1-T2 cluster, whereas the T3-cluster might have originated outside of the Camargue.

Several $R$. spiralis markers completely failed to amplify in one of the hybrid clusters. During the first generations after a hybrid lineage, severe chromosomal rearrangements can take place in a hybrid's genome including the deletion, inversion and translocation of chromosomal segments, until the chromosomes are stabilized (Adams and Wendel, 2005; Fontdevila, 2005; Baack and Rieseberg, 2007). Studies of polyploidization events in grasses found that up to $15 \%$ of the nuclear DNA can be eliminated already during the formation of an F1 hybrid but always from the same parental genome (Levy and Feldman, 2002). If these chromosomal rearrangements or new mutations affect the loci of the included microsatellites, or the primer binding sites, this might result in amplification failure. These chromosomal rearrangements are suggested as a mechanism that could increase reproductive isolation between the hybrid and one or both of the parental species (Schumer et al., 2015).

The R. maritima markers support the division into these two hybrid clusters, both hybrid clusters had several alleles that were not detected in the local $R$. maritima populations. These alleles might have accumulated over time through mutation in the hybrid lineage. However, it is also possible that they are the result of several backcrosses between these hybrid lineages and pure $R$. maritima populations in the past. The $R$. maritima populations included in this study were genetically poor, contrary to the hybrid populations. Selfing is a mechanism that reduces genetic diversity rather fast and selfing organisms are prone to extinction-recolonization cycles (Levin, 2010). As a result, it is possible that earlier local $R$. maritima populations contained 
different alleles that have disappeared over time due to extinction events or remained present in the seed bank (Vandvik et al., 2016). Triest and Sierens (2015) detected one pure R. maritima population in the Camargue, but this population had more alleles than the current five populations together. Although the same location did not harbor a $R$. maritima population during our field survey, it is possible that these alleles are still present in the seed bank or in local populations that were not detected during our sampling. Therefore, back-crossings between the hybrids and $R$. maritima at different moments in time might accumulate different $R$. maritima alleles in the hybrid lineages. Followed by outcrossing, these alleles are less prone to extinction in hybrid populations, compared to $R$. maritima populations (Todesco et al., 2016).

Although the majority of angiosperm hybrid lineages has multiple origins, outcrossing between hybrid lineages with different origins is not ubiquitous in the plant kingdom. Within the macrophyte genus Potamogeton for instance, many longliving hybrids are known, but the majority of these hybrids are sterile and only reproduce through clonal growth (Kaplan and Fehrer, 2006; Kaplan et al., 2009, 2018). The Asteraceae genus Tragopogon has two well-known and recurrently formed hybrid species, T. mirus and T. miscellatus that can reproduce sexual, but mainly through selfing. Outcrossing between different genotypes has been detected, but only between genotypes that are very similar (Symonds et al., 2010). However, within our study, the absence of high levels of clonality and inbreeding within each cluster suggests that these Ruppia hybrids can reproduce sexually with each other. The indications of recent gene flow between these two clusters even hints that outcrossing between hybrids with a different genetic history is possible, despite their genomic differences. Outcrossing between hybrids that result from different hybrid crosses can strongly increase the genetic diversity of a hybrid lineage with multiple origins. This could promote the adaptive potential of these hybrids, and hence increase the potential for hybrid speciation (Meimberg et al., 2009).

We could not detect F1 hybrids, nor were they detected in previous molecular studies (Triest and Sierens, 2015; Martínez-Garrido et al., 2016). It is possible that prezygotic reproductive barriers such as differences in ploidy or mating system prevent frequent hybridization between the tetraploid outcrossing $R$. spiralis and the diploid selfing $R$. maritima. Both differences in ploidy and mating system are considered as important reproductive barriers that promote speciation, although they are also known to be permeable to some extent (Brandvain and Haig, 2005; Goodwillie and Ness, 2013; Hülber et al., 2015). For instance, within the well-studied genus Mimulus several examples are known of species with different mating systems or ploidy that still hybridize. The predominantly selfing $M$. nasutus frequently hybridizes with its outcrossing relative M. guttatus (Brandvain et al., 2014). M. guttatus is also a good example of how a ploidy barrier can be permeable: this diploid species was introduced in the United Kingdom in 1812, where it hybridized with tetraploid M. luteus. The offspring, the sterile triploid hybrid species $M . x$ robertsii has multiple independent origins and is widespread throughout the United Kingdom (Vallejo-Marín and Lye, 2013). However, somehow M. x robertsii has overcome this hybrid sterility which resulted in the recently discovered fertile allopolyploid species $M$. peregrinus (VallejoMarín et al., 2015). Although triploids are dominantly sterile, the rare production of unreduced gametes that can cross with each other or backcross with one of the parental species, assures that a hybrid lineage can persist. This mechanism is also suggested in the genus Senecio where introgression from a diploid species into a tetraploid species results in a phenotype with flowers that are more attractive to pollinators (Chapman and Abbott, 2010). Some authors consider ecological factors such as differences in flowering time or pollination mode as even more important reproductive barriers than differences in ploidy or mating system (Brandvain et al., 2014; Briscoe Runquist et al., 2014): R. maritima flowers during spring whereas $R$. spiralis flowers during summer, when most $R$. maritima ponds have already dried up. As a result, successful fertilization between these two species is unlikely. If there is an overlap in flowering time and cross-fertilization can take place, a fertilized $R$. spiralis flower in a more permanent waterbody is more likely to produce a mature seed compared to a fertilized $R$. maritima flower in an almost dried-up pond. This might explain why no hybrids with a $R$. maritima chloroplast were detected so far (Triest and Sierens, 2015; Martínez-Garrido et al., 2016). Furthermore, although F1 hybrid formation is rare, this does not necessarily prevent the formation of well-established later-generation hybrid lineages. In the genus Iris, F1 hybrids between the two Louisiana species I. fulva and I. hexagona are rare. Nevertheless, the presence of well-established later-generation hybrid populations as well as high levels of adaptive introgression from one species into the other indicates that even rare hybridization might result in persistent hybrid lineages. Arnold (1997) suggests that once hybridization can overcome the reproductive barriers and F1 hybrids are produced, further hybridization is accelerated.

We detected fourteen samples that turned out to be backcrossings between $R$. maritima and the local hybrids. These samples are placed in subpopulation D1b that is found mixed with the pure $R$. maritima samples of population D1. They are the first described Ruppia hybrids with a $R$. maritima chloroplast. The reproductive barriers between $R$. maritima and the tetraploid outcrossing hybrids are similar to those between $R$. maritima and $R$. spiralis, which indicates that differences in mating system or ploidy are somewhat permeable barriers in this genus. However, both $R$. maritima and the hybrid populations were found in ponds that dry out during late spring. An overlap in flowering time between these two lineages seems hence more likely compared to $R$. maritima and $R$. spiralis. This would increase the chances of $R$. maritima as the maternal parent of a backcross. Followed by selfing, this could result in introgression of hybrid alleles into $R$. maritima. In selfing species, introgression could potentially be considered as a mechanism to rescue them from a build-up of deleterious alleles (Brandvain et al., 2014) or replace damaged alleles (Rieseberg, 2009). Although we could not detect any signs of frequent introgression in $R$. maritima, even low levels of introgression might be sufficient to maintain adequate levels of genetic diversity in this species. Triest and Sierens (2015) detected two populations with a $R$. spiralis chloroplast that only had a $R$. maritima ITS-region, which suggests strong 
introgression of $R$. spiralis toward $R$. maritima, potentially combined with ongoing $R$. spiralis chloroplast capture. These populations exhibited a higher genetic diversity and a lower inbreeding depression compared to pure $R$. maritima. On a large scale, the presence of Ruppia hybrids might act as a genetic reservoir for the genetically poor R. maritima, that could prevent this selfing species from its direct way to extinction (Todesco et al., 2016).

One limitation in our study is the absence of a good set of cross-amplifying markers that amplified in all samples. In the design of our multiplexes, we tried to overcome this problem by including markers RMB5, RMB15, and RMB53 in both multiplexes, but we did not foresee that only RMB15 could amplify successful in all populations. We also added diagnostic markers RUMR4 and RM3 to the $R$. spiralis multiplex but we omitted them from the $R$. maritima multiplex because they could not detect variation within pure $R$. maritima (Triest et al., 2017). Considering the structure of our data, we believe that our methods allowed us to detect a wide range of hybrids. For instance, a hybrid with a $R$. maritima chloroplast, would have at least some traces of heterozygosity or allele deviations from pure $R$. maritima. An F1-hybrid that was only amplified with the $R$. spiralis multiplex, would have different alleles for diagnostic markers RM3 and RUMR4. However, for good practice, we would advise to always carefully consider the composition of the multiplexes for the detection of hybrids and introgression. We strongly advice to include RM3 and RUMR4 in the $R$. maritima multiplex. We would also add some very specific markers of the other species in each species-specific multiplex, which would allow to detect extra alleles, that directly descend from hybridizations.

Flower peduncle length is often considered as the clearest distinguishing characteristic between $R$. spiralis and R. maritima. However, all populations that turned out to be Ruppia hybrids or pure $R$. maritima had fully grown flowers at the moment of sampling, all with short peduncles $(<5 \mathrm{~cm})$. Subsequently, we considered these hybrid populations as $R$. maritima during sampling. Previous reports of Ruppia hybrids also noticed that they wrongly identified Ruppia hybrids as Ruppia maritima in the field (Triest and Sierens, 2013, 2015; Martínez-Garrido et al., 2016). Verhoeven (1975) described the typical habitat of $R$. maritima in the Camargue as both temporary ditches and ponds, hence he might have possibly identified hybrids as $R$. maritima. This apparently common misidentification of hybrids as $R$. maritima probably partly contributes to the overestimation of the range and local abundance of $R$. maritima (Triest and Sierens, 2015). Therefore, we strongly recommend the use of genetic markers to identify different Ruppia species. Other studies on aquatic plants report a similar trend with a complex taxonomy within a genus that is resulting from cryptic species and hybridization events. Within the genus Najas for instance, N. marina, N. major- which was previously considered as subspecies of $N$. marina- and their subsequent sterile F1 hybrids can only be identified using molecular markers (Triest, 1988; Rüegg et al., 2019). The wide-ranging taxon N. flexilis turned out to be two morphologically similar but genetically distinct species (Les et al., 2015). In Potamogeton, a genus where hybridization is well described and recognized since the 18th century, several North American F1 hybrid species that were detected with molecular markers, turned out to be overlooked by previous morphological studies (Kaplan et al., 2009). Identification within the aquatic Ranunculus subgenus Batrachium has always been difficult and only recently, molecular studies revealed that the morphological highly diverse species complex $R$. penicillatus is probably rather a hybrid swarm than a distinct species group or a diverged hybrid lineage (ZalewskaGałosz et al., 2015). This cryptic diversity that is observed in many macrophyte taxa leads to an underestimation of biodiversity. Molecular markers and a better understanding of hybridization events are therefore crucial to understand the true biodiversity of inland aquatic systems.

\section{CONCLUSION}

The Camargue harbors both $R$. spiralis and R. maritima as well as several lineages of a hybrid origin. These encountered later-generation hybrid lineages co-occur with their parental species but are found in a different pond type. They are genetically differentiated from both parental species, although back-crossings between hybrids and - at least - $R$. maritima remain possible. Our dataset suggests that these two species and their hybrids have different habitat preferences, different reproductive ecologies and different ploidies. These differences could act as strong prezygotic reproductive barriers, preventing frequent hybridization and introgression, but are permeable to some extent. So far, these hybrids could not be identified based on morphology, which strongly increases the taxonomic complexity in this genus. However, many aquatic plants are morphologically cryptic, and it is not unlikely that, as in Ruppia, closer examination of their genetic composition would reveal similar complex structures of coexisting hybrids, backcrosses and parental species. Given that similar complexity has been found in the hybrid complexes of freshwater zooplankton such as Daphnia (Thielsch et al., 2017), such patterns of cryptic coexistence of hybrids and parental species may be even more common in freshwater environments than previously assumed.

\section{DATA AVAILABILITY STATEMENT}

The microsatellite data for both species are available at Dryad (doi: 10.5061/dryad.sn02v6x1c).

\section{AUTHOR CONTRIBUTIONS}

LB has performed the fieldwork and laboratory work, analyzed the data, and wrote the manuscript. LT helped during the field work and contributed laboratory equipment. LT and BV helped during data-analysis and manuscript writing. All authors contributed to the manuscript and approved the submitted version. 


\section{FUNDING}

This project was funded by the Vrije Universiteit Brussel (BAS42).

\section{ACKNOWLEDGMENTS}

Patrick Grillas and Marc Thibault (Tour du Valat), Véronique Paliard and Eric Coulet (La Capelière), and Claire Tetrel and Emmanuel Vialet (Domaine de la Palissade) were of great help for finding Ruppia populations and collecting plants. Tim Sierens

\section{REFERENCES}

Abbott, R. J., Albach, D. C., Ansell, S., Arntzen, J. W., Baird, S. J., Bierne, N., et al. (2013). Hybridization and speciation. J. Evol. Biol. 26, 229-246.

Adams, K. L., and Wendel, J. F. (2005). Novel patterns of gene expression in polyploid plants. Trends Genet. 21, 539-543. doi: 10.1016/j.tig.2005. 08.002

Arnaud-haond, S., Duarte, C. M., Alberto, F., and Serrão, E. A. (2007). Standardizing methods to address clonality in population studies. Mol. Ecol. 16, 5115-5139. doi: 10.1111/j.1365-294X.2007.03535.x

Arnold, M. L. (1997). Natural Hybridization and Evolution. New York, NY: Oxfor University Press, doi: 10.5860/choice.35-0883

Arnold, M. L., Ballerini, E. S., and Brothers, A. N. (2012). Hybrid fitness, adaptation and evolutionary diversification: lessons learned from Louisiana Irises. Heredity 108, 159-166. doi: 10.1038/hdy.2011.65

Baack, E. J., and Rieseberg, L. H. (2007). A genomic view of introgression and hybrid speciation. Curr. Opin. Plant Biol. 17, 513-518. doi: 10.1016/j.gde.2007. 09.001

Barrett, S. C. H., Eckert, C. G., and Husband, B. C. (1993). Evolutionary processes in aquatic plant populations. Aquat. Bot. 44, 105-145. doi: 10.1016/0304-3770(93) 90068-8

Barton, N. H. (2001). The role of hybridization in evolution. Mol. Ecol. 10, 551-568. doi: 10.1046/j.1365-294x.2001.01216.x

Barton, N. H., and Hewitt, G. M. (1985). Analysis of hybrid zones. Annu. Rev. Ecol. Syst. Vol. 16, 113-148. doi: 10.1146/annurev.es.16.110185.000553

Brandvain, Y., and Haig, D. (2005). Divergent mating systems and parental conflict as a barrier to hybridization in flowering plants. Am. Nat. 166, 330-338. doi: $10.1086 / 432036$

Brandvain, Y., Kenney, A. M., Flagel, L., Coop, G., and Sweigart, A. L. (2014). Speciation and Introgression between Mimulus nasutus and Mimulus guttatus. PLoS Genet. 10:e1004410. doi: 10.1371/journal.pgen.1004410

Briscoe Runquist, R. D., Chu, E., Iverson, J. L., Kopp, J. C., and Moeller, D. A. (2014). Rapid evolution of reproductive isolation between incipient outcrossing and selfing Clarkia species. Evolution 68, 2885-2900. doi: 10.1111/evo. 12488

Brochmann, C., Brysting, A. K., Alsos, I. G., Borgen, L., Grundt, H. H., Scheen, A. C., et al. (2004). Polyploidy in arctic plants. Biol. J. Linn. Soc. 82, 521-536. doi: 10.1111/j.1095-8312.2004.00337.x

Brock, M. A., and Lane, J. A. K. (1983). The aquatic macrophyte flora of saline wetlands in Western Australia in relation to salinity and permanence. Hydrobiologia 105, 63-76. doi: 10.1007/BF00025177

Buerkle, C. A. (2005). Maximum-likelihood estimation of a hybrid index based on molecular markers. Mol. Ecol. Notes 5, 684-687. doi: 10.1111/j.1471-8286.2005. 01011.x

Buerkle, C. A., Morris, R. J., Asmussen, M. A., and Rieseberg, L. H. (2000). The likelihood of homoploid hybrid speciation. Heredity 84, 441-451. doi: 10.1046/ j.1365-2540.2000.00680.x

Burke, J. M., and Arnold, M. L. (2001). Genetics and the fitness of hybrids. Annu. Rev. Genet. 35, 31-52. doi: 10.1146/annurev.genet.35.102401.085719

Burke, J. M., Carney, S. E., and Arnold, M. L. (1998). Hybrid fitness in the Louisiana irises: analysis of parental and F 1 performance. Evolution 52:37. doi: $10.2307 / 2410918$ helped with the DNA-extractions, PCR reactions and interpreting the microsatellite results.

\section{SUPPLEMENTARY MATERIAL}

The Supplementary Material for this article can be found online at: https://www.frontiersin.org/articles/10.3389/fpls.2020.00830/ full\#supplementary-material

MATERIAL S1 | Allele frequencies of each microsatellite, calculated for each population.

Chan, K. M. A., and Levin, S. A. (2005). Leaky prezygotic isolation and porous genomes: rapid introgression of maternally inherited DNA. Evolution 59, 720 729. doi: 10.1111/j.0014-3820.2005.tb01748.x

Chapman, M. A., and Abbott, R. J. (2010). Introgression of fitness genes across a ploidy barrier. New Phytol. 186, 63-71. doi: 10.1111/j.1469-8137.2009.03091.x

Cruzan, M. B., and Arnold, M. L. (1993). Ecological and Genetic Associations in an Iris Hybrid Zone. Evolution 47:1432. doi: 10.2307/2410158

De Silva, H. N., Hall, A. J., Rikkerink, E., McNeilage, M. A., and Fraser, L. G. (2005). Estimation of allele frequencies in polyploids under certain patterns of inheritance. Heredity 95, 327-334. doi: 10.1038/sj.hdy.6800728

den Hartog, C., and Kuo, J. (2007). “Taxonomy and biogeography of seagrasses," in Seagrasses: Biology, Ecology and Conservation, eds A. W. D. Larkum, R. J. Orth, and C. M. Duarte (Dordrecht: Springer Netherlands), 1-23. doi: 10.1007/9781-4020-2983-7_1

den Hartog, C., and Triest, L. (2020). A profound view and discourse on the typification and status of three confused taxa: ruppia maritima, $R$. spiralis and R. cirrhosa. Bot. Mar. 63, 229-239. doi: 10.1515/bot-2019-0045

Dufresne, F., Stift, M., Vergilino, R., and Mable, B. K. (2014). Recent progress and challenges in population genetics of polyploid organisms: an overview of current state-of-the-art molecular and statistical tools. Mol. Ecol. 23, 40-69. doi: $10.1111 / \mathrm{mec} .12581$

Duminil, J., and Di Michele, M. (2009). Plant species delimitation: a comparison of morphological and molecular markers. Plant Biosyst. 143, 528-542. doi: 10.1080/11263500902722964

Ellstrand, N. C., and Schierenbeck, K. A. (2000). Hybridization as a stimulus for the evolution of invasiveness in plants? PNAS 97, 7043-7050. doi: 10.1073/pnas.97. 13.7043

Fontdevila, A. (2005). Hybrid genome evolution by transposition. Cytogenet. Genome Res. 110, 49-55. doi: 10.1159/000084937

Gesti, J., Badosa, A., and Quintana, X. D. (2005). Reproductive potential in Ruppia cirrhosa (Petagna) Grande in response to water permanence. Aquat. Bot. 81, 191-198. doi: 10.1016/j.aquabot.2004.11.005

Gómez, A., and Carvalho, G. R. (2000). Sex, parthenogenesis and genetic structure of rotifers: Microsatellite analysis of contemporary and resting egg bank populations. Mol. Ecol. 9, 203-214. doi: 10.1046/j.1365-294X.2000.00849.x

Goodwillie, C., and Ness, J. M. (2013). Interactions of hybridization and mating systems: a case study in Leptosiphon (Polemoniaceae). Am. J. Bot. 100, 10021013. doi: 10.3732/ajb.1200616

Gramlich, S., Sagmeister, P., Dullinger, S., Hadacek, F., and Hörandl, E. (2016). Evolution in situ: hybrid origin and establishment of willows (Salix L.) on alpine glacier forefields. Heredity 116, 531-541. doi: 10.1038/hdy.2016.14

Harrison, R. G., and Larson, E. L. (2016). Heterogenous genome divergence, differential introgression and the origin and structure of hybrid zones. Mol. Ecol. 25, 2454-2466. doi: 10.1111/mec.13582.Heterogeneous

Howard, R. J., and Mendelssohn, I. A. (1999). Salinity as a constraint on growth of oligohaline marsh macrophytes. I. Species variation in stress tolerance. Am. J. Bot. 86, 785-794. doi: 10.2307/2656700

Hülber, K., Sonnleitner, M., Suda, J., Krejč́́ková, J., Schönswetter, P., Schneeweiss, G. M., et al. (2015). Ecological differentiation, lack of hybrids involving diploids, and asymmetric gene flow between polyploids in narrow contact zones of Senecio carniolicus (syn. Jacobaea carniolica, Asteraceae). Ecol. Evol. 5, 12241234. doi: 10.1002/ece3.1430 
Ito, Y., Ohi-Toma, T., Murata, J., and Tanaka, N. (2010). Hybridization and polyploidy of an aquatic plant, Ruppia (Ruppiaceae), inferred from plastid and nuclear DNA phylogenies. Am. J. Bot. 97, 1156-1167. doi: 10.3732/ajb.0900168

Ito, Y., Ohi-Toma, T., Murata, J., and Tanaka, N. (2013). Comprehensive phylogenetic analyses of the Ruppia maritima complex focusing on taxa from the Mediterranean. J. Plant Res. 126, 753-762. doi: 10.1007/s10265-013-0570-6

Ito, Y., Ohi-Toma, T., Nepi, C., Santangelo, A., Stinca, A., Tanaka, N. et al. (2017). Towards a better understanding of the Ruppia maritima complex (Ruppiaceae): notes on the correct application and typification of the names $R$. cirrhosa and R. spiralis. Taxon 66, 167-171. doi: 10.12705/661.11

Jombart, T. (2008). adegenet: a R package for the multivariate analysis of genetic markers. Bioinformatics 24, 1403-1405. doi: 10.1093/bioinformatics/btn129

Jombart, T., and Ahmed, I. (2011). adegenet 1.3-1: new tools for the analysis of genome-wide SNP data. Bioinformatics 27, 3070-3071. doi: 10.1093/ bioinformatics/btr521

Jombart, T., Devillard, S., and Balloux, F. (2010). Discriminant analysis of principal components: a new method for the analysis of genetically structured populations. BMC Genet. 11:94. doi: 10.1186/1471-2156-11-94

Jost, L. (2008). GST and its relatives do not measure differentiation. Mol. Ecol. 17, 4015-4026. doi: 10.1111/j.1365-294X.2008.03887.x

Kagawa, K., and Takimoto, G. (2018). Hybridization can promote adaptive radiation by means of transgressive segregation. Ecol. Lett. 21, 264-274. doi: 10.1111/ele.12891

Kamvar, Z. N., Brooks, J. C., and Grünwald, N. J. (2015). Novel R tools for analysis of genome-wide population genetic data with emphasis on clonality. Front. Genet. 6:208. doi: 10.3389/fgene.2015.00208

Kamvar, Z. N., Tabima, J. F., and Grünwald, N. J. (2014). Poppr?: an R package for genetic analysis of populations with clonal, partially clonal, and/or sexual reproduction. PeerJ 2:e281. doi: 10.7717/peerj.281

Kaplan, Z., and Fehrer, J. (2006). Comparison of natural and artificial hybridization in Potamogeton. Preslia 78, 303-316.

Kaplan, Z., Fehrer, J., Bambasová, V., and Hellquist, C. B. (2018). The endangered Florida pondweed (Potamogeton floridanus) is a hybrid: why we need to understand biodiversity thoroughly. PLoS One 13:e0195241. doi: 10.1371/ journal.pone.0195241

Kaplan, Z., Fehrer, J., and Hellquist, C. B. (2009). New hybrid hombinations hevealed by molecular analysis: the unknown side of North American pondweed diversity (Potamogeton). Syst. Bot. 34, 625-642. doi: 10.1600/ 036364409790139745

Kress, W. J., and Erickson, D. L. (2007). A two-locus global DNA barcode for land plants: the coding rbcL gene complements the non-coding trnH-psbA spacer region. PLoS One 2:e508. doi: 10.1371/journal.pone.0000508

Les, D. H., Cleland, M. A., and Waycott, M. (1997). Phylogenetic studies in Alismatidae, II: evolution of marine Angiosperms (Seagrasses) and hydrophily. Syst. Biol. 22, 443-463.

Les, D. H., Peredo, E. L., King, U. M., Benoit, L. K., Tippery, N. P., Ball, C. J., et al. (2015). Through thick and thin: cryptic sympatric speciation in the submersed genus Najas (Hydrocharitaceae). Mol. Phylogenet. Evol. 82, 15-30. doi: 10.1016/j.ympev.2014.09.022

Les, D. H., Sheldon, S. P., and Tippery, N. P. (2010). Hybridization in hydrophiles: natural interspecific hybrids in Najas (Hydrocharitaceae). Syst. Bot. 35, 736-744. doi: 10.1600/036364410x539826

Levin, D. A. (2010). Environment-enhanced self-fertilization: implications for niche shifts in adjacent populations. J. Ecol. 98, 1276-1283. doi: 10.1111/j.13652745.2010.01715.x

Levy, A. A., and Feldman, M. (2002). The impact of polyploidy on grass genome evolution. Plant Physiol. 130, 1587-1593. doi: 10.1104/pp.015727

Mallet, J., Besansky, N., and Hahn, M. W. (2016). How reticulated are species? Bioessays 38, 140-149. doi: 10.1002/bies.201500149

Mannino, A. M., and Graziano, M. (2014). Differences in the growth cycle of Ruppia cirrhosa (Petagna) Grande in a Mediterranean shallow system. Plant Biosyst. 2014:906511. doi: 10.1080/11263504.2014.906511

Mannino, A. M., Menéndez, M., Obrador, B., Sfriso, A., and Triest, L. (2015). The genus Ruppia L. (Ruppiaceae) in the Mediterranean region: an overview. Aquat. Bot. 124, 1-9. doi: 10.1016/j.aquabot.2015.02.005

Martin, S. H., and Jiggins, C. D. (2017). Interpreting the genomic landscape of introgression. Curr. Opin. Genet. Dev. 47, 69-74. doi: 10.1016/j.gde.2017.08.007
Martínez-Garrido, J., Bermejo, R., Serrão, E. A., Sánchez-Lizaso, J., and GonzálezWangüemert, M. (2017). Regional genetic structure in the aquatic macrophyte Ruppia cirrhosa suggests dispersal by waterbirds. Estuar. Coasts 40, 1705-1716. doi: 10.1007/s12237-017-0247-9

Martínez-Garrido, J., Serrão, E. A., Engelen, A. H., Cox, C. J., García-Murillo, P., and González-Wangüemert, M. (2016). Multilocus genetic analyses provide insight into speciation and hybridization in aquatic grasses, genus Ruppia. Biol. J. Linn. Soc. 117, 177-191. doi: 10.1111/bij.12666

Masembe, C., Muwanika, V. B., Nyakaana, S., Arctander, P., and Siegismund, H. R. (2006). Three genetically divergent lineages of the Oryx in eastern Africa: evidence for an ancient introgressive hybridization. Conserv. Genet. 7, 551-562. doi: 10.1007/s10592-005-9066-9

Meimberg, H., Rice, K. J., Milan, N. F., Njoku, C. C., and McKay, J. K. (2009). Multiple origins promote the ecological amplitude of allopolyploid Aegilops (Poaceae). Am. J. Bot. 96, 1262-1273. doi: 10.3732/ajb.0800345

Meirmans, P. G., and Hedrick, P. W. (2011). Assessing population structure: FSTand related measures. Mol. Ecol. Resour. 11, 5-18. doi: 10.1111/j.1755-0998. 2010.02927.x

Meirmans, P. G., and Liu, S. (2018). Analysis of molecular variance (AMOVA) for autopolyploids. Front. Ecol. Evol. 6:66. doi: 10.3389/fevo.2018.00066

Meirmans, P. G., Liu, S., and Van Tienderen, P. H. (2018). The analysis of polyploid genetic data. J. Hered. 109, 283-296. doi: 10.1093/jhered/esy006

Meirmans, P. G., and Van Tienderen, P. H. (2004). GENOTYPE and GENODIVE: two programs for the analysis of genetic diversity of asexual organisms. Mol. Ecol. Notes 4, 792-794. doi: 10.1111/j.1471-8286.2004.00770.x

Meirmans, P. G., and Van Tienderen, P. H. (2013). The effects of inheritance in tetraploids on genetic diversity and population divergence. Heredity 110 , 131-137. doi: 10.1038/hdy.2012.80

Moody, M. E., Mueller, L. D., and Soltis, D. E. (1993). Genetic variation and random drift in autotetraploid populations. Genetics 134, 649-657.

Nei, M. (1973). Analysis of gene diversity in subdivided populations. Proc. Natl. Acad. Sci. U.S.A. 70, 3321-3323. doi: 10.1073/pnas.70.12.3321

Olson, A., Paul, J., and Freeland, J. R. (2009). Habitat preferences of cattail species and hybrids (Typha spp.) in eastern Canada. Aquat. Bot. 91, 67-70. doi: 10.1016/ J.AQUABOT.2009.02.003

Park, D. S., Ellison, A. M., and Davis, C. C. (2018). Mating system does not predict niche breath. Glob. Ecol. Biogeogr. 27, 804-813. doi: 10.1111/geb.12740

R Development Core Team (2018). R: a language and environment for statistical computing. R Found. Stat. Comput. 1:409. doi: 10.1007/978-3-540-74 686-7

Reese, O. (1962). Zur intragenerischen taxonomie der gattung Ruppia L. ein cytosystematischer beitrag. Z. Bot. 50, 237-264.

Rieseberg, L. H. (1995). The role of hybrization in evolution: old wine in new skins. Am. J. Bot. 82, 944-953. doi: 10.2307/2445981

Rieseberg, L. H. (2009). Evolution: replacing genes and traits through hybridization. Curr. Biol. 19, R119-R122. doi: 10.1016/j.cub.2008.12.016

Rieseberg, L. H., Kim, S.-C., Randell, R. A., Whitney, K. D., Gross, B. L., Lexer, C., et al. (2007). Hybridization and the colonization of novel habitats by annual sunflowers. Genetica 129, 149-165. doi: 10.1007/s10709-006-9011-y

Rieseberg, L. H., and Soltis, D. E. (1991). Phylogenetic consequences of cytoplasmic gene flow in plants. Evol. Trends Plants 5, 65-84.

Ronfort, J., Jenczewski, E., Bataillon, T., and Rousset, F. (1998). Analysis of population structure in autotetraploid species. Genetics 150, 921-930.

Rüegg, S., Bräuchler, C., Geist, J., Heubl, G., Melzer, A., and Raeder, U. (2019). Phenotypic variation disguises genetic differences among Najas major and N. marina, and their hybrids. Aquat. Bot. 153, 15-23. doi: 10.1016/j.aquabot. 2018.11.005

Ryman, N., and Leimar, O. (2009). GST is still a useful measure of genetic differentiation-a comment on Jost's D. Mol. Ecol. 18, 2084-2087. doi: 10.1111/ j.1365-294x.2009.04187.x

Salamone, I., Govindarajulu, R., Falk, S., Parks, M., Liston, A., and Ashman, T. L. (2013). Bioclimatic, ecological, and phenotypic intermediacy and high genetic admixture in a natural hybrid of octoploid strawberries. Am. J. Bot. 100, 939-950. doi: 10.3732/ajb.1200624

Schumer, M., Cui, R., Rosenthal, G. G., and Andolfatto, P. (2015). Reproductive isolation of hybrid populations driven by genetic incompatibilities. PLoS Genet. 11:e1005041. doi: 10.1371/journal.pgen.1005041 
Soltis, D. E., and Soltis, P. S. (1993). Molecular data and the dynamic nature of polyploidy. CRC. Crit. Rev. Plant Sci. 12, 243-273. doi: 10.1080/ 07352689309701903

Soltis, D. E., Soltis, P. S., Pires, J. C., Kovarik, A., Tate, J. A., and Mavrodiev, E. (2004). Recent and recurrent polyploidy in Tragopogon (Asteraceae): cytogenetic, genomic and genetic comparisons. Biol. J. Linn. Soc. 82, 485-501. doi: $10.1111 / j .1095-8312.2004 .00335 . x$

Symonds, V. V., Soltis, P. S., and Soltis, D. E. (2010). Dynamics of polyploid formation in Tragopogon (Asteraceae): recurrent formation, gene flow, and population structure. Evolution 64, 1984-2003. doi: 10.1111/j.1558-5646.2010. 00978.x

Takahashi, Y., Iseki, K., Kitazawa, K., Muto, C., Somta, P., Irie, K., et al. (2015). A homoploid hybrid between wild Vigna species found in a limestone karst. Front. Plant Sci. 6:1050. doi: 10.3389/fpls.2015.01050

Thielsch, A., Knell, A., Mohammadyari, A., Petrusek, A., and Schwenk, K. (2017). Divergent clades or cryptic species? Mito-nuclear discordance in a Daphnia species complex. BMC Evol. Biol. 17:227. doi: 10.1186/s12862-017-1070-4

Thielsch, A., Völker, E., Kraus, R. H. S., and Schwenk, K. (2012). Discrimination of hybrid classes using cross-species amplification of microsatellite loci: methodological challenges and solutions in Daphnia. Mol. Ecol. Resour. 12, 697-705. doi: 10.1111/j.1755-0998.2012.03142.x

Todesco, M., Pascual, M. A., Owens, G. L., Ostevik, K. L., Moyers, B. T., Hübner, S., et al. (2016). Hybridization and extinction. Evol. Appl. 9, 892-908. doi: $10.1111 /$ eva. 12367

Totté, A., Delgado, A., Navarro, T., and Meerts, P. (2015). Narrow endemics of the Almeria Province (Andalusia, Spain) differ in their traits and ecological niche compared to their more widespread congeners. Folia Geobot. 50, 137-150. doi: 10.1007/s12224-015-9207-y

Tovar-Sánchez, E., and Oyama, K. (2004). Natural hybridization and hybrid zones between Quercus crassifolia and Quercus crassipes (Fagaceae) in Mexico: morphological and molecular evidence. Am. J. Bot. 91, 1352-1363. doi: 10.3732/ ajb.91.9.1352

Triest, L. (1988). A revision of the genus Najas L. (Najadaceae) in the Old World, Vol. 22. Brussels, Belgium: Academie Royale des Sciences d'Outre-Mer, 1-172.

Triest, L., Beirinckx, L., and Sierens, T. (2017). Lagoons and saltwater wetlands getting more diversity: a molecular approach reveals cryptic lineages of a euryhaline submerged macrophyte (Ruppia). Aquat. Conserv. Mar. Freshw. Ecosyst. 28, 370-382. doi: 10.1002/aqc.2863

Triest, L., and Sierens, T. (2010). Chloroplast sequences reveal a diversity gradient in the Mediterranean Ruppia cirrhosa species complex. 93, 68-74. doi: 10.1016/ j.aquabot.2010.03.007

Triest, L., and Sierens, T. (2013). Is the genetic structure of Mediterranean Ruppia shaped by bird-mediated dispersal or sea currents? Aquat. Bot. 104, 45-53. doi: 10.1016/j.aquabot.2014.02.004

Triest, L., and Sierens, T. (2014). Seagrass radiation after Messinian salinity crisis reflected by strong genetic structuring and out-of-Africa scenario (Ruppiaceae). PLoS One 9:e0104264. doi: 10.1371/journal.pone.0104264

Triest, L., and Sierens, T. (2015). Strong bottlenecks, Inbreeding and multiple hybridization of threatened European Ruppia maritima populations. Aquat. Bot. 125, 31-43. doi: 10.1016/j.aquabot.2015.05.001
Triest, L., Sierens, T., Menemenlis, D., and Van der Stocken, T. (2018). Inferring connectivity range in submerged aquatic populations (Ruppia L.) along European coastal lagoons from genetic imprint and simulated dispersal trajectories. Front. Plant Sci. 9:806. doi: 10.3389/fpls.2018.00806

Tsitrone, A., Kirkpatrick, M., and Levin, D. A. (2003). A Model for Chloroplast Capture. Evolution 57, 1776-1782. doi: 10.1111/j.0014-3820.2003.tb00585.x

Twyford, A. D., and Ennos, R. A. (2012). Next-generation hybridization and introgression. Heredity 108, 179-189. doi: 10.1038/hdy.2011.68

Vallejo-Marín, M., Buggs, R. J. A., Cooley, A. M., and Puzey, J. R. (2015). Speciation by genome duplication: repeated origins and genomic composition of the recently formed allopolyploid species Mimulus peregrinus. Evolution 69, 1487-1500. doi: 10.1111/evo.12678

Vallejo-Marín, M., and Lye, G. C. (2013). Hybridisation and genetic diversity in introduced Mimulus (Phrymaceae). Heredity 110, 11-122. doi: 10.1038/hdy. 2012.91

Vandvik, V., Klanderud, K., Meineri, E., Måren, I. E., and Töpper, J. (2016). Seed banks are biodiversity reservoirs: species-area relationships above versus below ground. Oikos 125, 218-228. doi: 10.1111/oik.02022

Verhoeven, J. T. A. (1975). Ruppia-communities in the camargue, France. Distribution and structure in relation to salinity and salinity fluctuations. Aquat. Bot. 1, 217-241. doi: 10.1016/0304-3770(75)90024-8

Verhoeven, J. T. A. (1979). The ecology of Ruppia-dominated communities in western Europe. I. Distribution of Ruppia representatives in relation to their autecology. Aquat. Bot. 6, 197-267. doi: 10.1016/0304-3770(79)90064-0

Weising, K., and Gardner, R. C. (2002). A set of conserved PCR primers for the analysis of simple sequence repeat polymorphisms in chloroplast genomes of dicotyledonous angiosperms. Genome 42, 9-19. doi: 10.1139/gen-42-1-9

Yu, S., Cui, M. Y., Liu, B., Wang, X. Y., and Chen, X. Y. (2009). Development and characterization of microsatellite loci in Ruppia maritima L. (Ruppiaceae). Conserv. Genet. Resour. 1, 241-243. doi: 10.1007/s12686-009-9059-y

Zalewska-Gałosz, J., Jopek, M., and Ilnicki, T. (2015). Hybridization in Batrachium group: controversial delimitation between heterophyllous Ranunculus penicillatus and the hybrid Ranunculus fluitans $\times$ R. peltatus. Aquat. Bot. 120, 160-168. doi: 10.1016/j.aquabot.2014.03.002

Zapfe, L., and Freeland, J. R. (2015). Heterosis in invasive F 1 cattail hybrids (Typha $\times$ glauca). Aquat. Bot. 125, 44-47. doi: 10.1016/j.aquabot.2015.05.004

Zou, P., Ng, W. L., Wu, W., Dai, S., Ning, Z., Wang, S., et al. (2017). Similar morphologies but different origins: hybrid status of two more semi-creeping taxa of Melastoma. Front. Plant Sci. 8:673. doi: 10.3389/fpls.2017.00673

Conflict of Interest: The authors declare that the research was conducted in the absence of any commercial or financial relationships that could be construed as a potential conflict of interest.

Copyright (c) 2020 Beirinckx, Vanschoenwinkel and Triest. This is an open-access article distributed under the terms of the Creative Commons Attribution License (CC BY). The use, distribution or reproduction in other forums is permitted, provided the original author(s) and the copyright owner(s) are credited and that the original publication in this journal is cited, in accordance with accepted academic practice. No use, distribution or reproduction is permitted which does not comply with these terms. 